\title{
Leonhard Thurneyssers Archidoxa (1569/75) und Quinta essentia (1570/74)
}

\section{Methodische Vorbemerkung}

Der folgende Beitrag gilt zwei in Versen abgefassten und deshalb hier als Dichtung bezeichneten Texten von Leonhard Thurneysser, die bisher in der Literaturwissenschaft, aber auch in der Medizin- und Wissenschaftsgeschichte keinerlei Aufmerksamkeit erfahren haben. Ursache ist offensichtlich, dass diese Texte den Erwartungen an das, was `Literatur` (und damit Gegenstand der Literaturwissenschaft) ist, genauso wenig entsprechen, wie sie mit ihrer Verbindung von Astrologie und Alchemie (in Versform) für die Medizin- und Wissenschaftsgeschichte von Interesse schienen. Die Frage, die ich im Folgenden - aus der methodischen Perspektive, wie sie dieser Band insgesamt formuliert - stellen möchte, lautet deshalb: Unter welchen disziplinären und methodischen Voraussetzungen ist es möglich, diese beiden Dichtungen zu ıverstehen`, das heißt die Rekonstruktion welcher sozial-, ideen- und literaturgeschichtlichen, welcher medien- und kulturgeschichtlichen Kontexte ist notwendig, um die konkrete Form und die Inhalte dieser beiden Dichtungen verständlich zu machen? - Dieser Fragestellung entsprechend geht es mir im Folgenden also nicht nur um das Verständnis dieser beiden Dichtungen als solcher, sondern immer auch um den methodischen Horizont.

\section{Die Archidoxa von 1569}

1569 erscheint die Archidoxa Leonhard Thurneyssers in Münster zum ersten Mal, schon hier im Selbstverlag, gedruckt von Johan Ossenbrug (»Gedruckt zu Munster in Westphalen durch Johan Osenbrug auff Verlegung H. Herr Leonhart Turneyssers zum Thurn.«). Der vollständige Titel lautet:

Archidoxa. Dorin der recht war Motus, Lauff vnd Gang/ auch heymlikait wirkung vnd krafft/ der Planeten/ Gstirns/ vnd gantzen Firmaments, Mutierung, vnd ausziechung aller Suptiliteten, vnd das Finfte wesen/ auss den Metallen/ Mineralia, Kreyter/ Wurtzen/ Seften/Steinen vnd aller andren wesenlichen dingen. Heimlikait des Buchs aller naturlichen Elementischen, und Menschlichen sachen/ Hantierung/ Könst/ Gwerb/ Arten/ Eygen-

Volkhard Wels, Berlin

Ә Open Access. (C) 2022 Volkhard Wels, publiziert von De Gruyter. (cc) BY Dieses Werk ist lizenziert unter einer Creative Commons Namensnennung 4.0 International Lizenz. https://doi.org/10.1515/9783110667004-011 
schafften/ vnd in suma/ alle verborgne Misteria, der Medicina, Alchemeya, vnnd anderen Freyen Könsten. [...] Durch Leonhart Thurneysser zum Turn/ Reymensweyss an Tag gebn. ${ }^{1}$

Das Buch, das mit diesem Titel beansprucht, das gesamte Naturwissen der Zeit und der menschlichen Künste sreimenweis` zu vereinigen, zählt 252 Seiten in Quarto. Davon entfallen auf den Verstext ca. 170 Seiten, jeweils mit 30 Versen pro Seite, was der gesamten Dichtung einen Umfang von ca. 5100 Versen gibt. Es handelt sich bei diesen Versen um äußerst unprätentiöse, achtsilbige Knittelreime.

Der Anfang des Textes konfrontiert den Leser mit einem Ich-Erzähler, der erwachend auf dem Bett liegt und über den Sinn seines mühevollen Lebens und die Undankbarkeit der Menschen nachdenkt. Als er die Sonne über den schneebedeckten Gipfeln Tirols aufgehen sieht, macht er jedoch seinen Frieden mit der Welt:

\author{
Als ich einsmols Lag auff dem betth/ \\ Wachent vnd gnueg geschloffen hett. \\ Bedacht mein leben hin vnd her. \\ Was angst mir zhnaden gangen wer/ \\ Auff Wasser/ Landt/ Mer/ Pruck vnd steg \\ Was trübsall/ kummer not elend/ \\ Mir je sy gstossen vnder dhendt. \\ Was vnglucks/ gferlickkayt vnd nott/ \\ Wie mir so offt noch gewest der Tott. \\ Wie souil Menschen von mir generdt/ \\ Den ich gedient hab/ vnd die geerdt.
}

\footnotetext{
1 Die beste bio-bibliographische Darstellung bietet Tobias Bulang: Leonhard Thurneysser. In: Wilhelm Kühlmann u. a. (Hg.): Frühe Neuzeit in Deutschland 1520-1620. Literaturwissenschaftliches Verfasserlexikon. Berlin, Boston 2017, Bd. 6, S. 283-298. Die Studien von Bulang (vgl. unten die entsprechenden Anm. 9, 28 und 44) waren grundlegend für diesen Beitrag. Aufgrund seiner Kenntnis des handschriftlichen Nachlasses ist zur Biographie nach wie vor unersetzlich Johann Karl Wilhelm Moehsen: Leben Leonhard Thurneissers zum Thurn, Churfürstl. Brandenburgischen Leibarztes. Ein Beitrag zur Geschichte der Alchymie, wie auch der Wissenschaften und Künste in der Mark Brandenburg gegen Ende des sechszehnten Jahrhunderts. In: Ders.: Beiträge zur Geschichte der Wissenschaften in der Mark Brandenburg von den ältesten Zeiten an bis zu Ende des sechszehnten Jahrhunderts. Berlin, Leipzig 1783, S. 1-198. Auch als Nachdruck München 1976. Die einzigen Hinweise auf die Archidoxa aus germanistischer Perspektive stammen von Joachim Telle: Thurneissers Archidoxa - medico-alchemische »Heimlichkeiten « in Form eines Traumberichts, und ebendort: Thurneissers Deß Menschen Circkel vnd Lauff - ein Hilfsmittel für Astrologen. In: Bibliotheca Palatina. Katalog zur Ausstellung. Textband. Hg. von Elmar Mittler. Heidelberg 1986, hier S. 351-353 und S. 353-354. Joachim Telle: Bemerkungen zum Viatorium spagyricum von Herbrandt Jamsthaler und seinen Quellen. In: Herbert Anton, Bernhard Gajek, Peter Pfaff (Hg.): Geist und Zeichen. Festschrift für Arthur Henkel. Heidelberg 1977, S. 427-442 weist Übernahmen Jamsthalers aus der Archidoxa und Quinta essentia nach.
} 
Die souil guttat von mir Je/

Entphangen hettent do vnd hie.

Auch wie die so vndanckbarlich/

Vmb vnschult neydten hasten mich.

Als ich bey mir solchs hertzlich betracht/

Solch grosser schmach vnd vnbill gedacht.

Mit ainem sufzen teiff auß grund/

Meinß hertzen gemyetz vnd Sell zu stund.

Sach ich auff in ein schnellen blick/

Den Himel an gar offt vnd tick.

Sagt Gott mein Schöpffer lob vnd tanck

Das ich solch alter hatt erlangt.

Jn dem sach ichs durchs venster glas/

Wie schön vn klar der Himel was.

Dem Turckys glich zuer selber zait/

So schön blaw wie der hemateit.

Stuendt auff mich yn das fenster legt/

Das Houpt ich hin vnd her bewegt.

Zu sehen wo das Fogel geschrey/

Her kem das ich so mancherley.

Hort hin vnd wyder vberall/

Van Trostlen/ Styglitz vnd Nachgall.

Darauß ich merckt des Morgens zait/

Hub auff vnd sach von feren weit.

Die hochen Alp spitz in Tyrol/

Die noch mit schne vnd eyss gantz wol.

Warent bedeckt den Wolcken gelich/

Auch sach ich wie von Osterricht/

Apollo mit seinm wagen reist.

Welchs glast am spitz der pergen gleist/

Die hele Sonn/ dem golt gelich.

Aurora schon lost sechen sich. (f. $D 1^{\mathrm{r}}$ f.)

Der Erzähler macht einen Spaziergang in den Wald und begegnet dort drei Frauen. Die erste ist sehr schön und reich gekleidet und bietet ihm einen köstlichen Wein an, den er jedoch ablehnt, da er vor dem Frühstück keinen Alkohol trinkt. Sie stellt sich als "glick [Glück] Reichtum ehr vnd gewalt« vor und verspricht, wenn er zu ihrem Diener werde, würde es ihm an diesen Dingen nicht mangeln. Der Erzähler lehnt jedoch mit Verweis auf eine lange Reihe historischer Exempel ab: Geld macht nicht glücklich, genauso wenig wie weltliche Macht. Die zweite Frau ist ärmlich gekleidet, bleich, gebeugt und von zahlreichen Krankheiten gezeichnet. Sie bietet ihm Armut und Unglück. Auch in ihren Dienst will der Erzähler nicht treten, er kennt ihn schon zu gut. Die dritte Frau - später wird sie »Frau Art« genannt, also die Kunst und Wissenschaft - tritt zu ihm, 
»hett füß gleich wie ein elephant/ | Bedeut Ehr/ Dapferkait vnd bstandt.« Sie ist weder besonders schön noch besonders reich, aber züchtig und angemessen gekleidet. Sie gibt nichts auf äußerliche Werte, dafür ist sie treu. Sie redet wenig, aber das Wenige ist vernünftig. Sie kennt die Bahnen der Planeten, kann lesen und rechnen, Instrumente spielen, kennt die Kräfte der Pflanzen und Kräuter, den menschlichen Organismus und was ihm nützt und schadet, kennt die chemisch-pharmazeutischen Praktiken (augmentieren, solvieren, fixieren usw.) und welche Kräfte die Mineralien haben. Sie kennt aber auch die Geographie, womit sie sich den Fürsten empfiehlt. Sie kann Geheimnisse für sich behalten, kennt die Gesetze der Architektur und der Ingenieurskunst genauso wie der Chirurgie und Medizin. All dieses Wissen bietet sie dem Erzähler an, wenn er ihr dienen wolle. Obwohl sie ihm gleichzeitig voraussagt, dass er viel Angst, Not, Trübsal, Spott und Schmach ertragen, zudem auf weiten Reisen viel erleiden werden müsse, nimmt der Erzähler das Angebot an. Die Frau führt ihn daraufhin zu einem Brunnen, mit dessen Wasser er sich die Augen auswaschen muss. Daraufhin erblickt er ein »schönes hauß«, »eim Kayserlichen hoff« gleich. Die Frau führt ihn in dieses Haus, das sich jedoch nur als eine Art Tor in eine andere Welt herausstellt.

Zu Beginn des zweiten Buchs der Archidoxa befindet sich der Erzähler jenseits des Tors auf einem Feld, ihm gegenüber sieben Städte. Die Führerin erklärt, dass den sieben Städten sieben Planeten, sieben Metalle, sieben Zeiten, sieben Orte, sieben Edelsteine usw. entsprechen und führt ihn sogleich in die erste Stadt, die Stadt Saturns. Sie ist aus Blei gebaut, also jenem Metall, das Saturn als Planet zugeordnet ist. Schon vor dem Stadttor begegnet ihnen in Gestalt eines alten, bärtigen und an Krücken gehenden Manns eine Personifikation dieses Planeten. Im Inneren der Stadt wird der Erzähler mit dem saturnischen Wissen bekannt gemacht, angefangen von den Gesetzen seiner Planetenbahn, über die ihm entsprechenden Körperteile, Gesteine, Kräuter, Metalle, seinen Wochentag und die Berufe, Werke und Tätigkeiten, die ihm zugeordnet sind. Es folgen dann nach demselben Schema Besuche in den anderen Städten, entsprechend den einzelnen Büchern der Archidoxa: Jupiter (Zinn), Mars (Eisen), Sonne (Gold), Venus (Kupfer), Merkur (Quecksilber), Mond (Silber).

Innerhalb der einzelnen Bücher treten die narrativen Teile gegenüber der Belehrung, die der Erzähler durch »Frau Art« erfährt, weitestgehend zurück. Es handelt sich dabei - gemessen am Stand der Zeit - nicht um neues oder ungewöhnliches Wissen, sondern um gängige Überzeugungen, so dass dem gesamten Werk eher der Status einer gereimten, von Exkursen durchzogenen Enzyklopädie zukommt. Entferntes Vorbild könnte der Zodiacus vitae (1536) von Marcellus Palingenius Stellatus gewesen sein. Dieser Text lag seit 1564 in einer deutschen Übersetzung von Johannes Spreng vor, Thurneysser (der zu diesem Zeitpunkt 
noch kein Latein kann, wie er selbst am Ende des Textes mitteilt: »in dem Latein/ Jn dem ich nit erfahren bin «, f. Aa3 ${ }^{r}$ ) könnte ihn also gekannt haben. ${ }^{2}$ Beide Texte orientieren sich in ihrer Gliederung an astrologischen Modellen (Tierkreis und Planeten), die zum Anlass werden, die gesamte menschliche Welt zu durchlaufen. Beide Texte verflechten moralische Betrachtungen mit Naturwissen. Ähnlich wie der Zodiacus gewinnt die Archidoxa gelegentlich satirische Qualitäten, etwa bei der Aufzählung der Sekten, die sich im Gefolge der Reformation bildeten $\left(\mathrm{f} . \mathrm{T} 4^{\mathrm{r}}\right.$ ). Allerdings ist der Zodiacus vitae ein typisch humanistischer Text, der seine Bildungsvoraussetzungen überall offensiv zur Schau stellt. Eine Verwechslung von Demosthenes und Diogenes, wie sie Thurneysser im ersten Buch unterläuft (»Wie Demosthenes beweyset das/ | Der was viel reicher in seim vaß.«, f. D4 ${ }^{\mathrm{v}}$ ), wird man beim Verfasser des Zodiacus wohl kaum finden. Dennoch: Abgesehen von diesem Text lassen sich wenig mögliche Vorbilder bestimmen. Mit der alchemischen Dichtung des Mittelalters und der Frühen Neuzeit, wie sie Joachim Telle untersucht hat, hat die Archidoxa jedenfalls wenig gemein. ${ }^{3}$ Auch mit der gleichnamigen, Paracelsus zugeschriebenen Schrift, die zeitgleich 1569 erschienen ist, gibt es (im Unterschied allerdings zur Quinta essentia) keine Gemeinsamkeiten, obwohl Thurneysser seinen Titel sicherlich von dieser übernommen hat. ${ }^{4}$

Das interessanteste an diesem Text ist damit jedoch noch gar nicht erwähnt. Die Archidoxa besteht nämlich nicht nur aus einem gereimten Text, der die Attribute der sieben Planeten entwickelt, sondern aus einem insgesamt dreispaltigen Text, in dem diese Beschreibung nur den Mittelteil bildet. Links davon stehen Quellen- und Referenzangaben, Belegstellen und Querverweise. Rechts

2 Zu dieser Übersetzung sowie zur Lehrdichtung der Zeit allgemein vgl. Wilhelm Kühlmann: Wissen als Poesie. Zu Formen und Funktionen der frühneuzeitlichen Lehrdichtung im deutschen Kulturraum des 16. und 17. Jahrhunderts. In: Joachim Telle (Hg.): Alchemie und Poesie. Deutsche Alchemikerdichtungen des 15. bis 17. Jahrhunderts. Berlin, Boston 2013, S. 1-84, hier S. 26 ff. sowie Wilhelm Kühlmann: Wissen als Poesie (s. Anm. 2), S. 61-77.

3 Vgl. stellvertretend die gesammelten Studien in Joachim Telle: Alchemie und Poesie (s. Anm. 2) sowie dort den Beitrag von Didier Kahn: La poésie alchimique dans l'Europe médiévale et moderne, S. 85-148. Allgemein zum Verhältnis von Astrologie und Alchemie vgl. Telle: Von der Meisterschaft der sieben Planeten. Zu einer astroalchemischen Lehrdichtung im Basilius-Valentinus-Corpus. In: Ders.: Alchemie und Poesie (s. Anm. 2), S. 689-723. Telle bestreitet dort (ebd., S. 698) Thurneyssers Archidoxa den Charakter einer astroalchemischen Dichtung, weil er die alchemischen Inhalte vermisst. Vgl. dagegen unten mein Argument, dass die Archidoxa und die Quinta essentia komplementär angelegt sind.

4 Die (pseudo-)paracelsische Archidoxa erschien 1569 lateinisch in Krakau, 1570 deutsch in München. Thurneysser stand mit wichtigen Frühparacelsisten in brieflichem Kontakt (vgl. die Angaben in Wilhelm Kühlmann, Joachim Telle (Hg.): Corpus Paracelsisticum. Bd. II. Tübingen 2004, bes. S. 436 ff.) und dürfte von der Edition zumindest gehört haben. 


\section{\&us Erfte \&ư

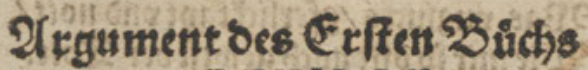 Der ARCHIDOXA.}

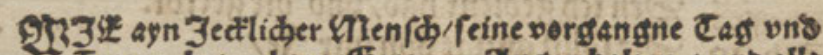
Catten betradten, (5ott vor Zlugen balten, vno alle Baitt 'Runft ' Degfs bait vnd Derftandt / fur Keydtum / Get walt vno Pracht erwelen/ougent Rieben / vnd allen rodimut verabren foll. 2lud was erübfal / Zngft / Klodt / vnd Ef far/ einem Ronftliebenden/pnber 2lugen ftoft/wĩ zu bande getb/wћ

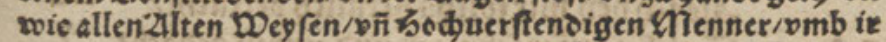
setonetrey wo vnd gutat/die fey oem Dold wno Datterland bes

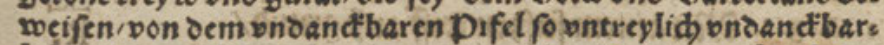
lid vnd gnbillid, belontt worben find , Ond oie jufonft dek froumen $A$ rt $/ D a s$ gefpred vnd ber Contract fo mit ir gemadbe.

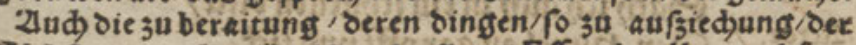

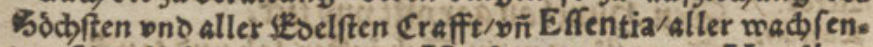
e. Den Simplicien/pno aud 3 ue Mutierunge / oer 7. Metallew. Dienftlidf fynot.

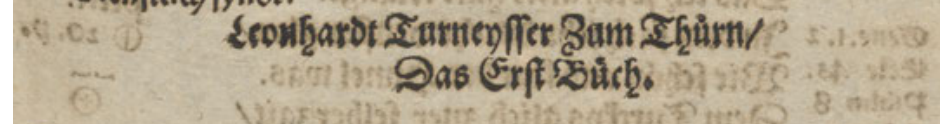

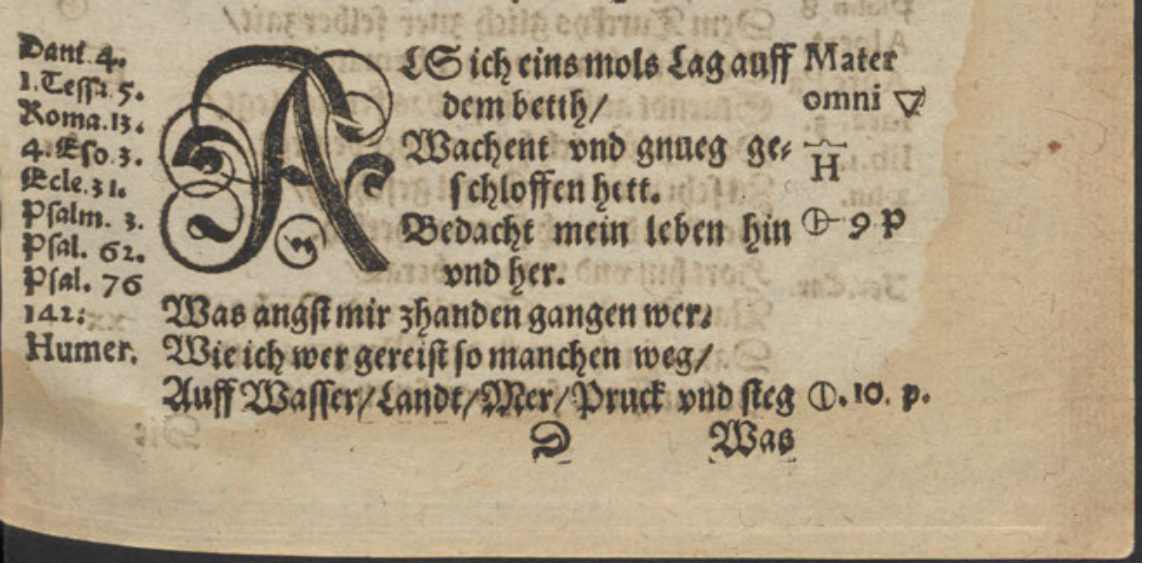

Abb. 1 und 2: Leonhard Thurneysser: Archidoxa. Münster 1569, f. $D^{r}$ und $D^{v}$. Abbildungen aus dem Exemplar der Staatsbibliothek Berlin, Sign. Mu 1991. 


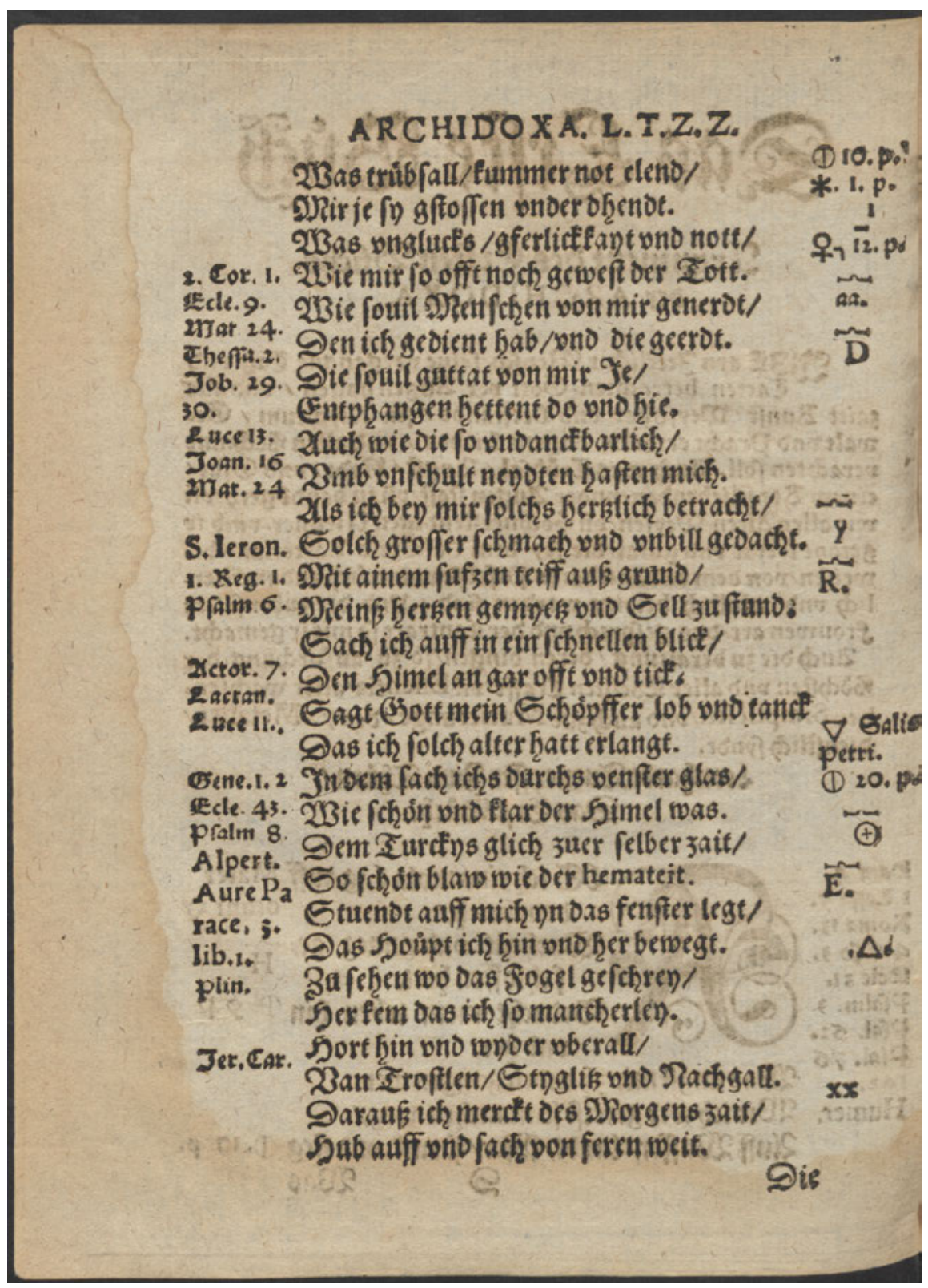

Abb. 1 und 2 (fortgesetzt) 
davon stehen chemische Rezepte, in der Symbolsprache der Zeit verschlüsselt, und zwar ohne, dass der Gegenstand des Rezepts genannt werden würde oder die einzelnen Rezepte voneinander abgesetzt wären. Die acht Bücher der Archidoxa sind solcherart in der rechten Textspalte von einer beständigen und nicht abreißenden Reihe chemischer Symbole und Arbeitsanweisungen begleitet.

Dieses äußerst ungewöhnliche Verfahren begründet Thurneysser in seiner Vorrede. Nach dem Verlust des vollständigen Wissens im Sündenfall Adams hätte durch die Güte Gottes eine partielle und allmähliche Rückgewinnung des präadamitischen Wissens eingesetzt. Dieses Wissen konnte nach Thurneysser auf drei Arten vermittelt werden:

Erstlich in Carmen/ Reymen/ auß Metrischem grund/ zierlich vnd Könstlich/ als die Poeten/ die den lauff der Welt/ vnd alten vergangnen geschichten vnd tatten/ sampt den fabeln/ gesetzt vnnd int feder verfast haben.

Neben Moses, David und Salomon nennt Thurneysser Orpheus, Homer, Hesiod, Ovid, Vergil u. a. als Beispiele für diese Wissensvermittlung in Versform. ${ }^{5}$ Wenn Thurneysser in der Quinta essentia schreibt, er hätte das Buch in »Reimen « verfasst, weil diese »kurtzweilig zu lesen « seien, ${ }^{6}$ dürfte das denselben Sachverhalt bezeichnen: die poetische Form gilt vor allem als Erleichterung des Lesens, wie sie in den Anfangsstadien der Menschheit wichtig war. Damit würde Thurneysser eine Überzeugung vertreten, die in der Frühen Neuzeit unhinterfragt und allgegenwärtig ist: dass die Versform älter ist als die Sachprosa und diese sich durchsetzte, als die Menschheit dem Stadium der Kindheit entwachsen war. Wenn Thurneysser für die Archidoxa und die Quinta essentia die Versform wählt, dürfte er damit an der Anciennität partizipieren wollen, die diesen Verstexten zukommt: es ginge nicht um poetische Verfahrensweisen im engeren Sinne, sondern um die >Patina < uralter Weisheitslehren.

Zweitens hätten die großen Gelehrten der Antike und des Mittelalters zwar das Fundament gelegt, auf dem die Nachwelt bauen könne, jedoch hätten sie sich auch oft geirrt. So hätte sich Aristoteles in der Anatomie geirrt, Galen und Hippokrates in ihren astronomischen Berechnungen und in ihrem Wissen über die Wirkkräfte der Pflanzen, Platon und Strabo in der Geographie, andere in der Astronomie, vor allem aber in der Astrologie.

\footnotetext{
5 Thurneyssers Desinteresse an der Poetik spiegelt sich in seiner Aufzählung der Gedichtformen, wenn es dort heißt, etliche von diesen Dichtern hätten sich des "Heroicum« bedient, etliche des "Hexametrum, etliche Asclepiadum etliche Iampicum [sic] etliche Pentametrum, oder Elegiacum vnd das Bucolicum«. Die Unterschiede zwischen Gattungen und Versmaßen sind Thurneysser offenbar nicht klar und dürften ihn auch nicht interessiert haben. 6 Leonhard Thurneysser: Quinta essentia. Leipzig 1574, S. 201 (Marginalie).
} 
Während all diese Gelehrten ihr Wissen offen und unverschlüsselt dargestellt hätten, gäbe es drittens mit der Alchemie eine Kategorie von Gelehrten, die ihr Wissen nur verschlüsselt dargestellt hätten: Entweder, indem sie einzelne Wörter gegenteilig verwendet hätten (`Schwarz`statt >Weißく, >Feuer`statt >Wasser ), oder durch Buchstabenveränderungen (»Beyl« statt »Leyb«) oder indem sie Symbole statt Wörtern benutzt hätten (wofür die chemischen Zeichen das Beispiel sind) oder schließlich, indem sie sich »vertunckelter reden« bedient hätten. Damit ist die Arkansprache der Alchemie gemeint, in der etwa das Quecksilber als Drache figuriert, weil es »schlipferig vnbleyblich vnd nit zu behalten « (f. B3 ${ }^{\mathrm{v}}$ ) sei. $^{7}$

Diese Techniken der Verschlüsselung seien erfunden worden, um die großen Geheimnisse der Natur einerseits vermitteln zu können, andererseits aber sie angesichts der »grosse[n] lasterhafftige[n] vndanckbarkait des menschlichen geschlechts « nicht zu profanieren und »die Perlen nit fur die schwein vnd das Heyligtum nit fur die hund « zu werfen, wie es mit einem (für die alchemische Arkansprache klassischen) Zitat von Matth. 7.6 heißt. Das alchemische Wissen sollte transferiert, aber nicht profaniert werden (B4 ${ }^{\mathrm{r}}$, falsch paginiert als B3). Die »Heimlichkeit« der Alchemie, der geheimnisvolle Charakter eines Wissens, das nicht in aperter, verständlicher Form verfasst ist, macht allerdings auch einen nicht unwesentlichen Reiz dieses Wissens aus. Thurneysser verwendet es als verkaufsförderndes Element, wenn es auf der Rückseite des Titelblatts heißt:

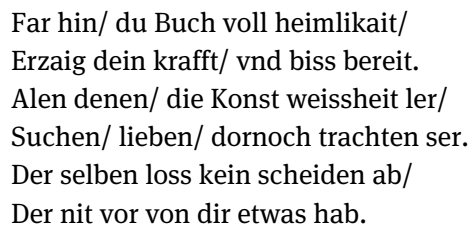

In die Tradition dieser >Heimlichkeit`stellt sich Thurneysser mit seiner Archidoxa, wenn er drei Arten des Verständnisses in Anspruch nimmt. Erstens habe er in den »Reymen«, also in der Mittelspalte des Textes, die Wirkungen der Planeten auf alle Geschehnisse und menschlichen Zustände und Krankheiten sowie die entsprechenden pharmazeutischen Kuren aufzeigen wollen (f. B4 ${ }^{\mathrm{V}}$ ). Zweitens habe er

\footnotetext{
auserthalben des sententzes/ den die reymen fur sich selbert geben [...] in denselbigen Reymen etliche wörter/ die zu den (ad Marginem) verzaichneten Caracteres dienen/ die do mit sampt den zaichen/ so dargegen stand/ auch einen besonderen sententz machen/ vnd geben etc.
}

7 Stellvertretend zur Tradition der Verrätselung alchemischen Wissens vgl. Lawrence M. Principe: The Secrets of Alchemy. Chicago 2013. 
Diese Bedeutung sei die alchemisch bewirkte Veränderung der Metalle und Mineralien sowie die Destillation der Kräuter und Wurzeln, durch die deren Kräfte als das »Finfte Wesen « - also die Quinta essentia - sausgezogen « und therapeutisch nutzbar gemacht werde (f. $4^{\mathrm{v}}$ f.). Drittens seien in den »Reymen « alle großen Krankheiten sowie die alchemischen »arcana «, mit denen sie therapiert werden könnten, enthalten, allerdings »nit gar außtruckenlich/ sonder alein verborgenlich/ doch warhafftig vnd der massen beschriben/ das der recht sententz durch nachsinnen/ wol kan vnd mag verstanden werden.« Um dieses »nachsinnen « zu erleichtern, stünden »ad marginem« die »zeichen«, die die alchemischen Prozesse bedeuteten (f. $\mathrm{B} 5^{\mathrm{r}}$ ).

Was der Unterschied zwischen der zweiten und dritten Lesart des Buches sein soll, ist schwer zu erkennen, genauso wie die behauptete Verbindung der »Reymen« mit »den (ad Marginem) verzaichneten Caracteres«. Mir ist es nicht gelungen, die »etlichen wörter« innerhalb der »Reymen«, die mit »den (ad Marginem) verzaichneten Caracteres [...] einen besonderen sententz machen « sollen, herauszufinden - wenn das überhaupt so $\mathrm{zu}$ verstehen ist, dass die am Rand mitgeteilten Rezepte in einer inhaltlichen (oder auch nur mnemotechnischen) Verbindung zum narrativen Gehalt der mittleren Textspalte stehen.

Die Symbole und Abkürzungen, die Thurneysser in den Marginalien verwendet, werden in einem eigenen Kapitel zu Beginn des Textes unter dem Titel »Bedeutnus der Caracter vnd Zeichen « (f. $\mathrm{C}^{\mathrm{r}}{ }^{\mathrm{r}}$ ) aufgeschlüsselt.

Es handelt sich allerdings um die in der chemischen Praxis gängigen Zeichen und Abkürzungen, wie sie insbesondere in handschriftlichen Aufzeichnungen und Laborbüchern verwendet wurden. Diese Zeichen waren nie wirklich geheim gewesen. Interessanter ist diese Aufschlüsselung eher deshalb, weil sie die von Thurneysser in der Vorrede propagierte Praxis der Geheimhaltung doch scheinbar konterkariert. Die chemische Symbolsprache der rechten Textspalte erscheint als bloße Notationstechnik, nicht mehr als kryptographische Chiffrierung. Thurneysser - dieser Verdacht drängt sich auf - bedient sich eher des änigmatischen Charakters der alchemischen Symbolsprache, als tatsächlich alchemisches Wissen zu verbergen. Damit soll allerdings nicht gesagt sein, dass die chemischen Anweisungen nicht ernst zu nehmen wären. Dass dem nicht so ist, belegt schon der »Index« (f. $\mathrm{Bb}^{\mathrm{r}}$ ff.), mit dem Thurneysser die Archidoxa versehen hat und der ausschließlich die chemischen Prozesse und Substanzen erfasst, die die linke Spalte des Textes bilden. Das Buch ist also dafür angelegt, die entsprechenden Rezepte und Substanzen unabhängig von einer linearen Lektüre auffindbar zu machen. Wie wichtig die linke Spalte Thurneysser war, zeigt außerdem die eigene »Errata«-Liste (f. $\mathrm{Bb}^{\mathrm{r}}$ ff., doppelt paginiert), die Thurneysser dem Druck anfügen musste. Der Setzer hatte offensichtlich Probleme gehabt, die Symbole auseinanderzuhalten, so dass diese Liste relativ lang geraten ist. Auch diese Liste zeigt, 


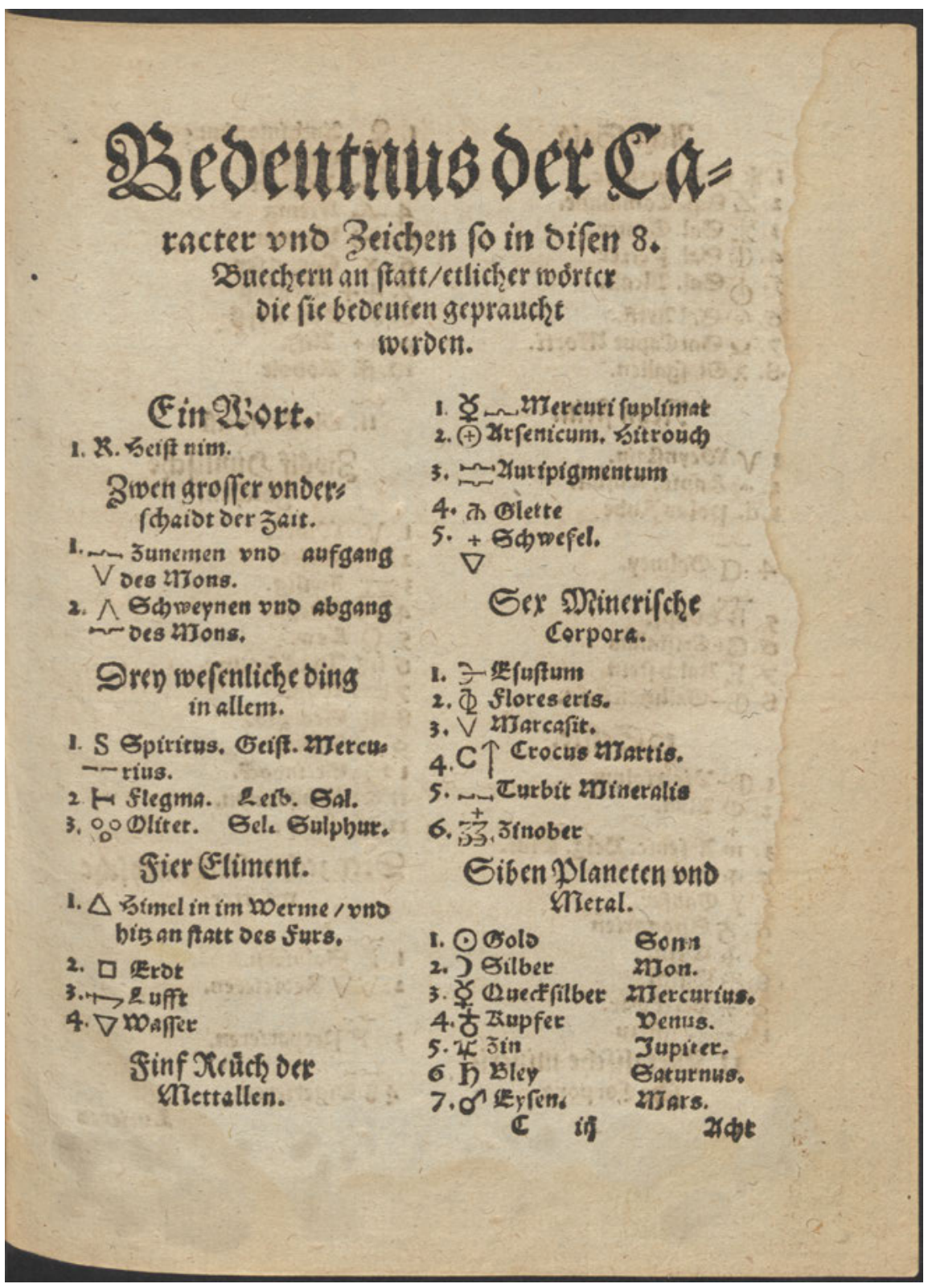

Abb. 3: Leonhard Thurneysser: Archidoxa. Münster 1569, f. C iij ${ }^{r}$. Abbildung aus dem Exemplar der Staatsbibliothek Berlin, Sign. Mu 1991. 
dass die Rezepte ernst gemeint sind und die Archidoxa damit als Rezeptbuch gedacht sind.

Auf der anderen Seite - und damit partizipiert Thurneysser wiederum am änigmatischen, geheimnisvollen Charakter der Alchemie - ist der Archidoxa nach der Vorrede eine ausfaltbare Tafel beigebunden, die den Titel Sechs vnd zweintzig Houptstuck trägt.

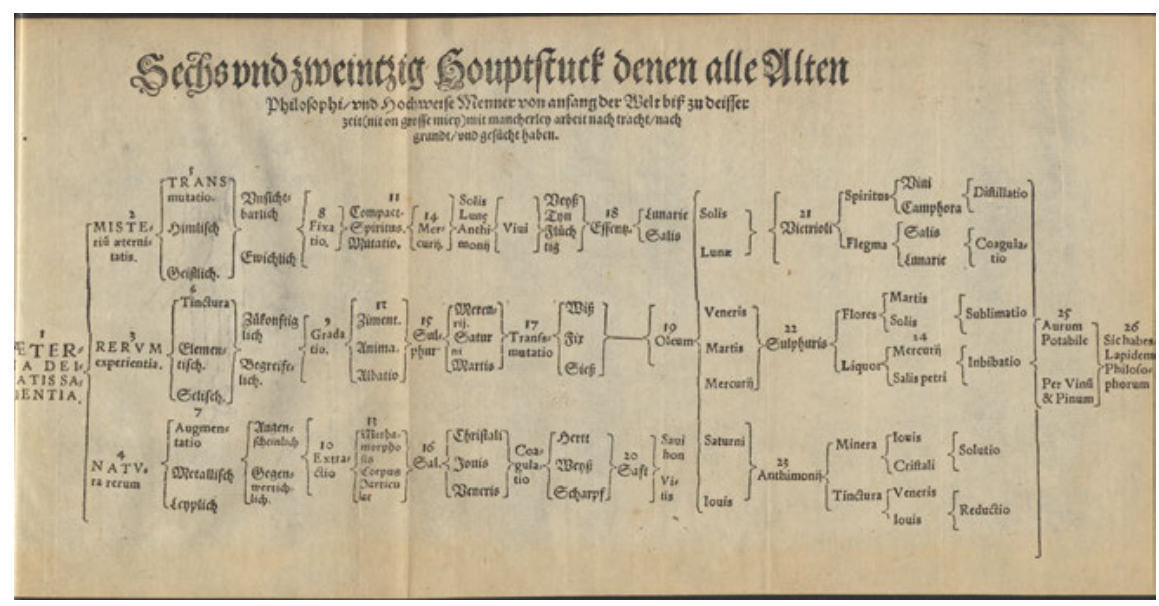

Abb. 4: Leonhard Thurneysser: Archidoxa. Münster 1569, "Sechs vnd zweintzig Houptstuck«, unpag., nach der Widmung eingebunden. Abbildung aus dem Exemplar der Staatsbibliothek Berlin, Sign. Mu 1991.

In dieser Tafel werden auf ramistische Weise alchemische Prozesse und Substanzen gegliedert, wobei an erster Stelle »die ewige Weisheit der Gottheit« steht, am anderen Ende der Stein der Weisen. Das Prinzip der dazwischen geschalteten Gliederung ist (zumindest mir) nicht erkenntlich. Auch hier übernimmt Thurneysser mit der ramistischen Darstellung vielleicht nur eine Modeerscheinung der Zeit.

Relativ konservativ erscheint dagegen auf den ersten Blick die Praxis der Quellenverweise in den Marginalien der linken Textspalte. Allerdings nimmt diese in der Frühen Neuzeit ubiquitäre Technik auf den zweiten Blick bei Thurneysser ebenfalls merkwürdige Formen an. Warum etwa bei dem oben zitierten Textanfang, wenn der Erzähler aufwacht und auf seinem Bett liegt, in den Marginalien auf Dan. 4, 1. Thess. 5 und Röm. 13 verwiesen wird, ist nicht ersichtlich. Wenn etwas später, als die Sonne aufgeht (»Auch sach ich wie von Osterrich/ I Apollo mit seim wagen reist «), in der Marginalie auf Vergil verwiesen wird, ohne weitere Stellenangabe, scheint der einzige Bezug zum Text die Nennung 
des antiken Sonnengottes zu sein, die die Nennung eines antiken Autors in der Marginalie nach sich zieht. Auch weitere Stichproben ergeben keinen anderen Befund: Die Quellenverweise in den Marginalien machen einen derartig willkürlichen Eindruck, dass man gelegentlich geneigt ist, Thurneyssers Praxis für eine Satire auf die Gepflogenheiten der späthumanistischen Gelehrtenkultur zu halten.

Dieser Eindruck dürfte allerdings täuschen: Thurneysser ist seine dreispaltige Technik der Wissensvermittlung so wichtig, dass er sie als Grund für die Wahl des Titels nennt. Archidoxa habe er das Buch genannt, weil in ihm das ganze Wissen der Welt gelehrt werde und ein solches Buch bisher nicht existiert habe. Diese Einmaligkeit des Buchs steht allerdings wiederum in einem merkwürdigen Verhältnis zu der unmittelbar folgenden Entstehungsgeschichte. Entstanden sei das Buch nämlich während einer Schiffsreise, auf der er sonst nichts zu tun gehabt hätte (f. B5 ${ }^{\mathrm{v}}$ ). Ähnlich heißt es am Ende des Buchs unter dem Titel Beschluß vnd Entschuldigung des Tichters, er, Thurneysser, habe dieses Buch verfasst, »domit zu kurtzen mir die zait«. Merkwürdig ist das, weil man ja nicht erwarten würde, dass ein solcherart einmaliges Buch aus Langeweile entsteht.

Noch merkwürdiger wird der Text, wenn man die bisher noch nicht erwähnten Abbildungen betrachtet, die dem Buch beigegeben sind. ${ }^{8}$ Jedem der acht Kapitel sind je zwei Abbildungen vorangestellt, wobei die Positionierung der Abbildungen de facto dem jeweiligen Buchbinder anheimgestellt war, der diesbezüglich auch von Thurneysser auf den ersten Seiten des Buches angesprochen wird (»An den Buchbinder«), selbstverständlich ebenfalls in Versen. Acht »Figuren«, schreibt Thurneysser, fänden sich in diesem »buchlein«, und diese acht »Figuren« sollten jeweils dort eingebunden werden, wo der entsprechende Planet behandelt würde. Jede »Figur« besteht aus zwei Tafeln, einer »Motus«Tafel und einem »Ast $«$.

Die »Motus«-Tafeln bestimmen die Bewegung des jeweiligen Planeten durch die Dekane (den Tierkreis). Für jeden einzelnen Tag (die schwarzen und weißen Punkte unterhalb der Monatsnamen stehen für die Tage jedes Monats) lässt sich auf diese Weise bestimmen, in welchem >Haus` (im Einfluss welches Tierkreiszeichens) er steht. Die zweite Art von Tafeln beschreibt Thurneysser als »Zirckel«, »radt« und »Ast«. Es handelt sich jeweils um einen Ast, der spiralförmig um einen Mittelpunkt gewunden ist und auf dessen Blättern bestimmte Begriffe ste-

8 Die Tafeln fehlen in einigen Exemplaren, so in einem der beiden Exemplare der Staatsbibliothek zu Berlin (Sign.: Mu 2007) und in dem Exemplar der Herzog August Bibliothek Wolfenbüttel (Sign.: Nd 775). Ich zitiere im Folgenden nach dem zweiten, vollständigen Exemplar der Staatsbibliothek zu Berlin (Sign.: Mu 1991). 


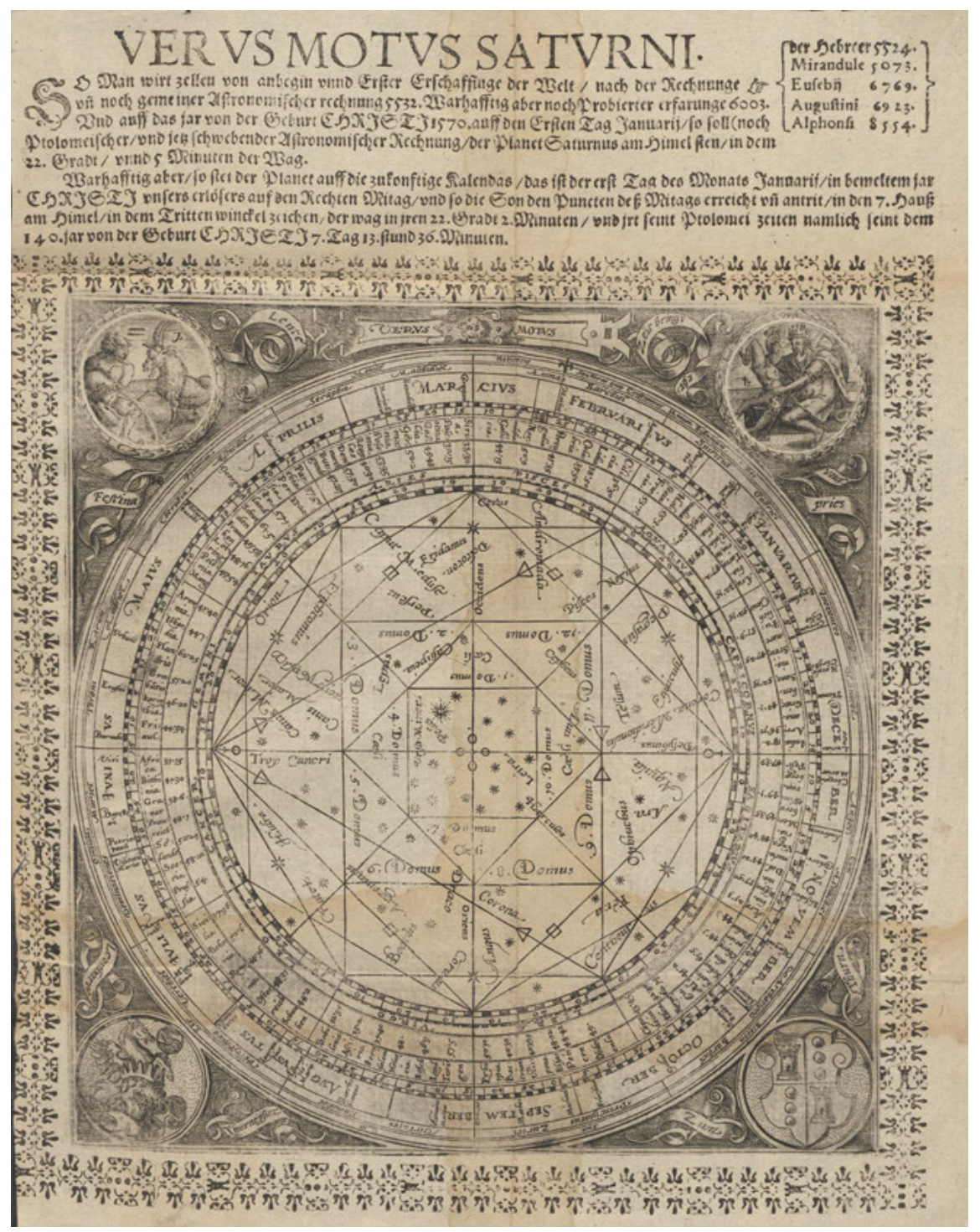

Abb. 5 und 6: Leonhard Thurneysser: Archidoxa. Münster 1569: »Motus«-Tafel und »Ast« zu Saturn, unpag., eingebunden vor f. F3 ${ }^{r}$. Abbildung aus dem Exemplar der Staatsbibliothek Berlin, Sign. Mu 1991. 


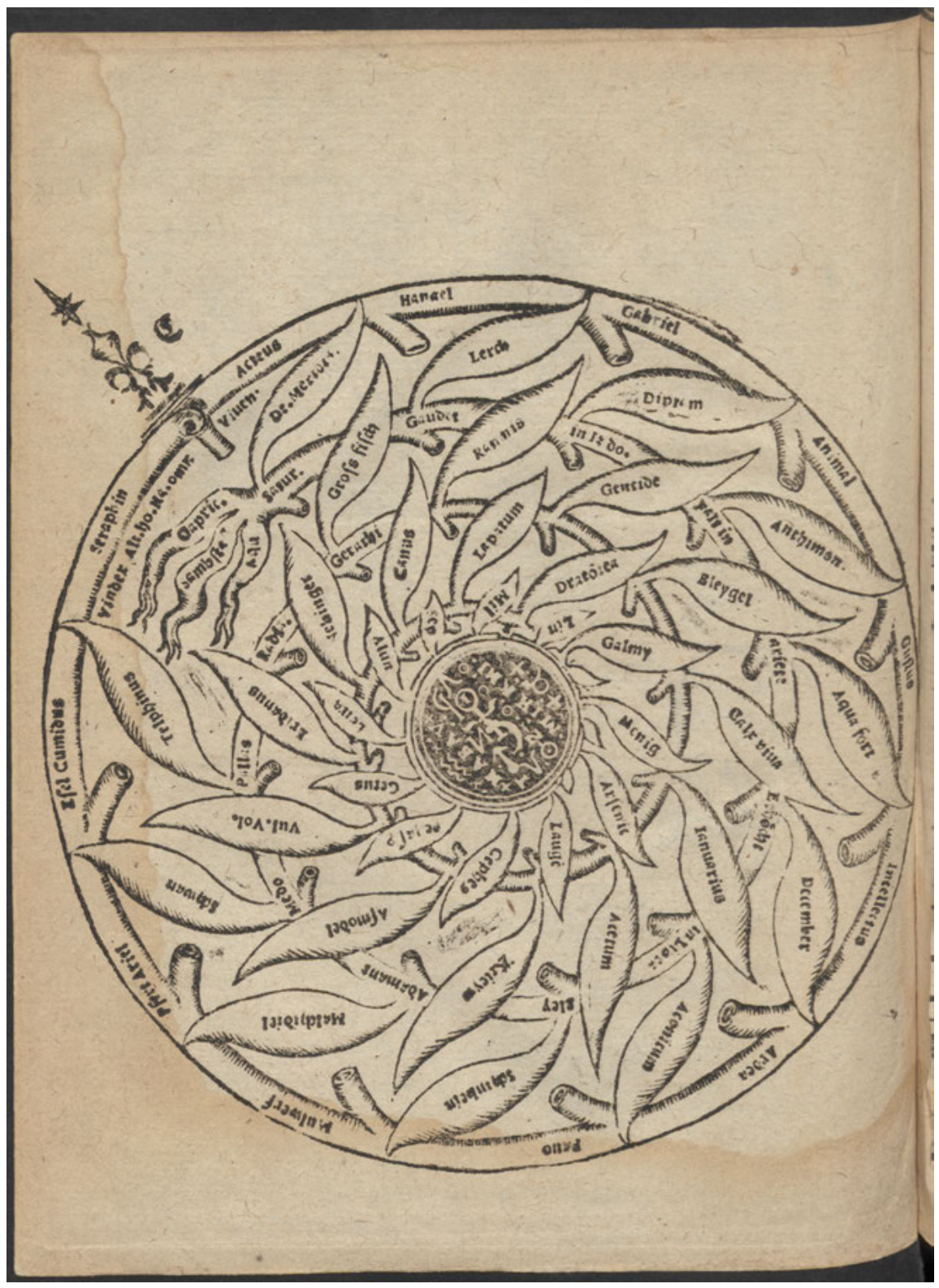

Abb. 5 und 6 (fortgesetzt) 
hen. Diese >Ast «-Abbildungen waren wohl mit »A«, »B«, »C« usw. markiert, so dass der Buchbinder sie den jeweiligen Kapiteln und »Motus«-Tafeln zuordnen konnte. Die Anweisung an den Buchbinder lautet:

Leyms auff papir/ das es vmge. | Schneydt zwischen blettern/ vnnd dem stam | Die feldung durch/ hinweg all sam. | Domit ein jeder sechen kan/ | Wo/ wie/ vnd in waß gradus stan. | Alle Planeten/ auff jeden tag/ | Leyms wol/ das sich nicht verrucken mag. | Wers vmt reybt/ der wirt sechen drinen/ | Figuren/ wunderlicher sinnen. ～(unpag., "An den Buchbinder «)

Die »Ast «-Abbildungen waren demnach dazu bestimmt, ausgeschnitten zu werden, so dass der »Ast « als eine Vovelle (wie solche drehbaren Elemente in der Buchwissenschaft genannt werden) auf die »Motus«-Tafeln aufgelegt und gedreht werden konnte. Damit konnte man dann für jeden Tag sehen, in welchem Grad die Planeten standen. Deshalb findet sich links oben auf jeder »Ast«-Abbildung ein Pfeil: der Rand um den Ast herum sollte weggeschnitten werden, so dass man den Pfeil jeweils auf der darunterliegenden »Motus«-Abbildung auf den entsprechenden Tag einstellen konnte. Die »wunderlichen sinnen«, die man durch das »umtreiben « des Astes sehen konnte, waren dann die auf den Blättern des Astes verzeichneten Gemütszustände, Körperteile, Krankheiten, chemischen Substanzen, Affekte, Engel, Tiere, Pflanzen, Säfte usw. Es handelt sich mithin bei diesen Tafeln um die Elemente, aus denen sich jeder Käufer des Buchs sein medizinisches Horoskop selbst erstellen konnte, für jeden Tag aufs Neue. Zumindest buch- und mediengeschichtlich ist das eine äußerst innovative Idee.

\section{Die Archidoxa von 1575}

1575 erscheint die Archidoxa ein zweites Mal, diesmal von Thurneysser nicht nur verlegt, sondern auch gedruckt. 1575 ist Thurneysser nämlich bereits »Churfürstlich Brandenburgisch Bestalter Leibs Medicus«, wie auf dem Titelblatt vermerkt ist. Als solcher verfügt er jetzt im Grauen Kloster in Berlin über eine eigene Druckerei (darauf wird zurückzukommen sein). Das ist der Ausstattung des gesamten Bandes (nicht mehr in Quarto, sondern im repräsentativeren Folio-Format) anzumerken, von dem zweifarbig gedruckten Titelblatt über die Drucktypen und die Initialen bis zu den Abbildungen. Es handelt sich bei der Ausgabe von 1575 ohne Zweifel um einen äußerst aufwändig gestalteten Druck, ohne Vergleich zu der Ausgabe von 1569. Ebenfalls schon auf dem Titelblatt wird eine weitere Neuerung gegenüber der Ausgabe von 1569 vermerkt: "Zum andern mal vnd jetz von newen gemert/ vnd sampt dem verstand der Caracter an tag geben«.

Was damit gemeint ist, zeigt schon der erste Blick auf den Text. 


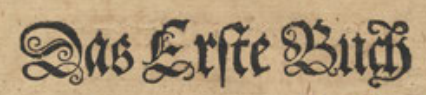

\section{2roumentbes Exften $\mathfrak{B u c h s}$} orr ARCHIDOXA.

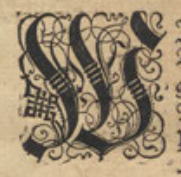

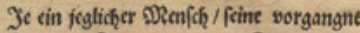
Iag/ vito Iatten berrachten/ Bott vor Zlus

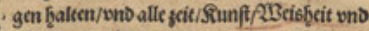
3artantot / für Xiciçtum / Bctwatt / vnno pracḩt erivelen / ougent fieben / vno allen - Sochmut verachicen fol. Zuch mas Trübfal/

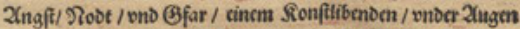

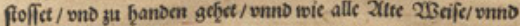
Sochatuerftendige D2enner/vntb jir getone troyw/ vnnb gutat/ oie

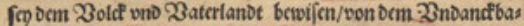
ren püfel fo ontrcuilich/nno and fbarlich/vĩ vnbillich belont wors

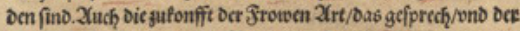
Eontract fo mit ir gmacht. 2luch bic gubercittung oeren oingen/

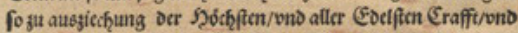
Effentia/ aller wachfonoch Simplicien / vno auch zu Mutierne ge orr 7. Metallen/oienflich finot.

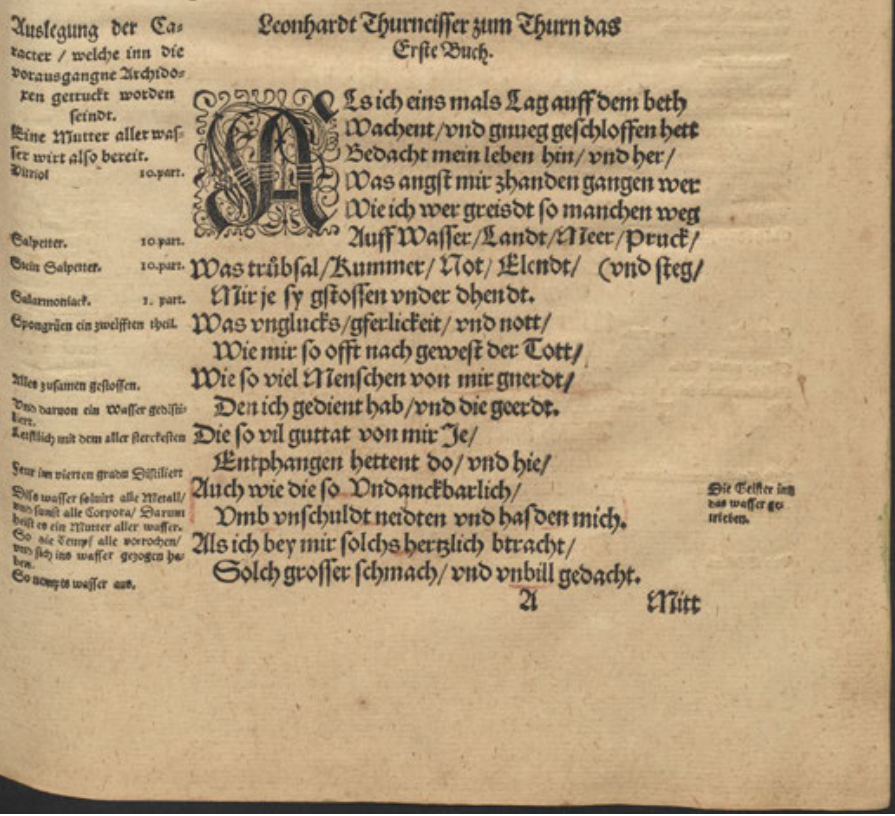

Abb. 7: Leonhard Thurneysser: Archidoxa. Berlin 1575, f. A' (= S. 1'). Abbildung aus dem Exemplar der Staatsbibliothek zu Berlin, Sign. $4^{\circ} \mathrm{Mu} 1999 \mathrm{~b}$. 
Dieser ist zwar immer noch dreispaltig gedruckt, aber in der linken Spalte finden sich jetzt nicht mehr Quellenverweise und Belegstellen (oder, wie man vielleicht besser sagen müsste, Listen von Autoritäten), sondern ausgeschriebene, das heißt nicht in Symbolsprache formulierte, chemische Rezepte. Über der linken Textspalte steht gleich zu Beginn: »Auslegung der Caracter/ welche inn die vorausgangne Archidoxen getruckt worden seindt.« Darauf folgt sogleich das erste Rezept, ein »Wasser«, das jeweils zu $10 \%$ aus Vitriol, Salpeter und Steinsalpeter, zu $1 \%$ aus »Salarmoniack « und zu $12 \%$ aus »Spongrüen « besteht. Diese Bestandteile werden »zusamen gestossen«, »darvon ein Wasser gedistilliert« und »letstlich mit dem aller sterckesten Feur im vierten gradu Distiliert«. »Diss wasser soluirt alle Metall/ vnd sunst alle Corpora/ Darum heist es ein Mutter aller wasser. So die Tempf alle vorrochen/ vnd sich ins wasser gezogen haben. So nempts wasser aus. «Das ist offensichtlich ein präzises und im Labor umsetzbares Rezept für ein Lösungsmittel, vermutlich Salpetersäure. In der rechten Textspalte finden sich noch weitere, laborpraktische Präzisierungen oder Beschreibungen dessen, was die hergestellten Produkte können.

In welchem Verhältnis die beiden Marginalspalten zu den »Reymen « in der Mitte stehen, ist auch in dieser zweiten Ausgabe noch nicht klar. Die entsprechende Leseanweisung in der Vorrede hat Thurneysser kaum geändert, sondern lediglich dort, wo es nötig war, ins Präteritum gesetzt. Was in der ersten Fassung noch »verborgenlich durch Caracter vnd Zeichen « ausgedrückt und deshalb erst »durch langs nach sinnen « verständlich geworden sei, könne man jetzt einfach lesen. Wo »ad marginem« die »zeichen« gestanden seien, stünden jetzt »die Heitern ausstruckten wort «, aus denen man die Anweisungen für die konkreten Rezepte »der grund Konst Alchemiae« entnehmen könne (f. $4^{\mathrm{v}}$ ). Eine Begründung, warum die Rezepte jetzt »austruckenlich« formuliert werden und das »lange Nachsinnen « wegfällt, sucht man vergebens. Weder wird klar, was der Mehrwert der »heimlichkeit« in der ersten Fassung war, noch, warum diese »heimlichkeit« jetzt aufgegeben wird. Was aber durch diese zweite Fassung unbezweifelbar wird: Die Rezepte sind labortechnisch umsetzbare Anweisungen.

Es gibt jedoch noch weitere Änderungen. Weggefallen (und damit offensichtlich also auch verzichtbar gewesen) ist die Tafel mit den Sechs vnd zweintzig Houptstuck der Alchemie, die von der Weisheit Gottes zum Stein der Weisen führte. Weggefallen ist natürlich auch die nicht mehr nötige Aufschlüsselung der chemischen Symbolsprache. Stattdessen findet sich gleich am Anfang des Buchs ein »Register aller Kunstück wo die hierin ad Margine zufinden«, aufgeschlüsselt nach den einzelnen Büchern. Die wichtigste Änderung aber betrifft die Planetentafeln und die `Äste`, die es in der ersten Fassung jedem Käufer ermöglicht hatten, sein eigenes Horoskop zu erstellen. Diese Tafeln fehlen in der zweiten Fassung - und das, obwohl sie auf dem Titelblatt (im Gegensatz zur 
Ausgabe von 1569) eigens vermerkt sind: "sampt dem auszug/ vnd Verstandt des Astrolabij/ vnd aller Zircklen Caracter/ vnd Zeichen.« Da die Vorrede an den Buchbinder mit ihrer Arbeitsanweisung sich jedoch noch an derselben Stelle findet, scheint es, als seien die Tafeln ursprünglich geplant gewesen, dann aber - während des Drucks - weggefallen.

Diese Vermutung bestätigt sich, denn im selben Jahr erscheint - ebenfalls in

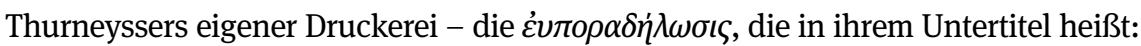

Das ist ein gnügsame vberflussige vnd ausfierliche erklerunge/ oder erleuterunge/ vnd verstandt der Archidoxen/ Leonhart Thurneissers zum Thurn/ [...] Darin mancherley Dieffsinniger explicationes/ vnd eröffnungen vieler streittiger sachen/ von Göttern/ Engeln/ Teuffeln/ Menschen/ Tieren/ Caracteren/ Siglen/ Zaubereyen/ Gespensten/ Kreutteren/ Metallen/ Mineren/ vnd Gesteinen eröffnet. Sunderlich aber von den Himlen/ Gestirn/ Planeten/ Zeichen/ vnd Bilderen/ Item von den Elementen/ Commetten/ vnd deren Krefften/ Faculteten/ Wirckungen/ Betriben/ Arten/ vnd Aigenschafften/ sambt dem Astrolabio/ vnd dem gebrauch desselbigen/ durch welches Natiuiteten gestellt/ Gluck/ Ungluck/ Kranckheitten/ Tod/ vnd Leben/ Krieg/ Tewrung/ vnd anders/ nach Astronomischer weis/ vnd Mathematischer Rechnung ordentlich/ vnd baldt kan Calculirt/ vnd beschrieben/ vnd ohne sunderliche müeh erkandt werden.

Thurneysser kommentiert damit sein eigenes Werk und druckt diesen Kommentar gleichzeitig mit diesem Werk selbst - eine durchaus singuläre Erscheinung in der Frühen Neuzeit (soweit ich sehe), die man mit einigem Recht als >Über-

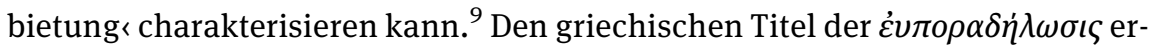
klärt Thurneysser in der Vorrede, als »vberflüssige föllige erklerung/ oder erleüterung vnd verstandt/ meiner vor ausgangnen Archidoxen«, zusammenge-

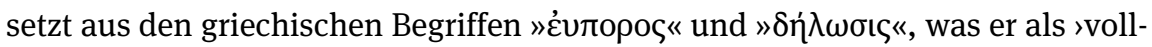
ständige Erklärung`verstanden haben möchte (f. $a \times 3^{\mathrm{v}}$ ).

Auch hier ist man im ersten Moment geneigt, eine Satire auf den späthumanistischen Kult um die griechischen Sprachkenntnisse zu vermuten. Aber Thurneysser meint seine Sprachschöpfung ernst. Ähnlich sind nämlich die Namen der Personen entworfen, die als Gesprächsteilnehmer auftreten. `Frau Art aus

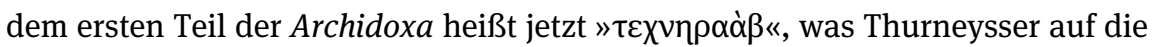

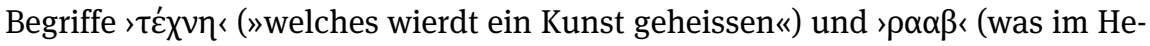
bräischen das Fruchtbare und >wohl Gedeihende` bedeute) zurückführt (f. B2 ${ }^{\mathrm{r}}$ ). Warum der aus dem Hebräischen abgeleitete Begriff » $\alpha \alpha \beta$ « griechisch transkribiert wird, ist nicht klar. Der zweite Gesprächsteilnehmer heißt »

9 Vgl. in diesem Sinne die Studie von Tobias Bulang: Überbietungsstrategien und Selbstautorisierung im »Onomasticon« Leonhard Thurneyssers zum Thurn. In: Jan-Dirk Müller u. a. (Hg.): Aemulatio. Kulturen des Wettstreits in Text und Bild (1450-1620). Berlin, Boston 2011, S. 699-729. 
was - so Thurneysser - jemanden bezeichnen würde, der viele Sprachen beherrsche und im Geheimen bleibe (f. $B 2^{r}$ ). Bei einigen weiteren Gesprächsteilnehmern, die keine tragende Rolle spielen, scheint Thurneysser persönlichen Bekannten ein Denkmal gesetzt zu haben, wie die in den Marginalien vermerkten Anfangsbuchstaben nahelegen (vgl. zum Beispiel f. B2 ${ }^{\mathrm{v}}$ ).

Laut einer Vorbemerkung »an den Guthertzigen Leser« hätte Thurneysser den Text eigentlich in Szenen und Akte einteilen wollen, »[n]ach Attischer weis/ wie die Poeten | Jr gdicht vor zeit beschrieben thetten«. (f. $\mathrm{A}^{\mathrm{v}}$ ) Zumindest der erste Teil des folgenden »Colloquium« (der gleichzeitig als neuntes Buch

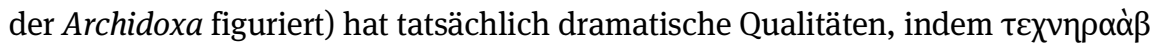

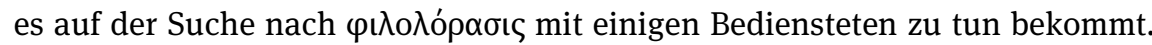
Die folgende Erklerung vber die acht Bücher der Archidoxen (die gleichzeitig als zehntes Buch dieser Archidoxa figuriert) ist dann im Kern aber ein Gespräch zwi-

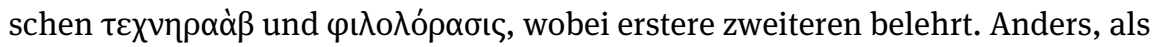
es der Titel erwarten lässt, wird jedoch keine Erklärung der Archidoxa geboten, sondern eine detaillierte, sich über ca. 280 Seiten und mehr als zehntausend Verse erstreckende Erklärung des Astrolabiums.

Dieses »Astrolabium« ist dem Buch selbst nicht mehr beigegeben, sondern wurde - gedruckt im sogenannten Supergroßfolio-Format -, separat ausgeliefert und deshalb auch heute in den Katalogen separat katalogisiert, obwohl es

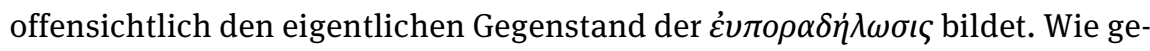
sagt: das gesamte zehnte Buch mit seinen über zehntausend Versen ist der Erklärung dieses »Astrolabiums « gewidmet. ${ }^{10}$ Nachweisbar sind von diesem Buch nur noch sehr wenige Exemplare. ${ }^{11}$

Thurneysser hat die Grundidee, die schon den Tafeln in der Ausgabe von 1569 zugrunde lag, weiter ausgebaut. Die Tafel, die den »Motus« des jeweiligen Planeten anzeigt, dient als Grundlage für sechs Volvellen, die auf ihr zu befesti-

10 Da das Astrolabium separat gedruckt wurde, wird es in den Bibliothekskatalogen auch separat katalogisiert - und da es kein eigenes Titelblatt hat, unter dem Titel der ersten Tafel, nämlich Dess Menschen Circkel vnd Lauff. Auf die Zusammengehörigkeit der Bände hat bereits Giovanni Mazzini: L'»Astrolabium« di Leonard Thurneisser zum Thurn. In: Miscellanea Giovanni Mercati 6 (1946), S. 414-431 hingewiesen. Zur Geschichte der Volvelle, ebenfalls mit einer Rekonstruktion von Thurneyssers Astrolabium, vgl. Gianfranco Crupi: Volvelles of Knowledge. Origin and Development of an Instrument of Scientific Imagination ( $13^{\text {th }}-17^{\text {th }}$ centuries). In: JLIS.it 10,2 (2019), S. 1-27.

11 Susan Karr Schmidt: Sternenglaube und Alchemie. Thurneissers Papierastrolabien. In: Christian Heitzmann (Hg.): Die Sterne lügen nicht. Astrologie und Astronomie im Mittelalter und in der Frühen Neuzeit. Wolfenbüttel 2008, S. 106-110 spricht S. 107 von ca. zwölf Exemplaren. Karr Schmidt weist (ebd., S. 107) auch darauf hin, dass die Astrolabien nur bis 1583 benutzbar waren. Sie konnten schwarz-weiß oder handkoloriert erworben werden. 
gen waren. Dazu gehören Darstellungen des Fixsternhimmels, der aus dem Exemplar von 1569 bekannte >Ast (interessanterweise hier anders beschriftet, was ja eigentlich Zweifel an dem vermittelten Wissen wecken könnte) sowie ein schlangenförmiger `Lebenspfeilı. Die Staatsbibliothek Berlin hat die Bauweise dieses Astrolabiums an einem ihrer Exemplare anschaulich vorgeführt und Susan Karr Schmidt anhand des Wolfenbütteler Exemplars beschrieben. ${ }^{12}$ Die

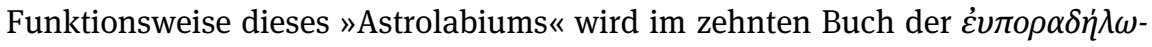
$\sigma \iota \varsigma$ ausführlich erklärt, wobei sich elf Kapitel jeweils den einzelnen »Zirckeln« widmen und ein abschließendes Kapitel dem »Usus Jebung/ vnd gebrauch des Astrolabiums mit klaren exempeln welcher massen dormit gepracticiert« gilt.

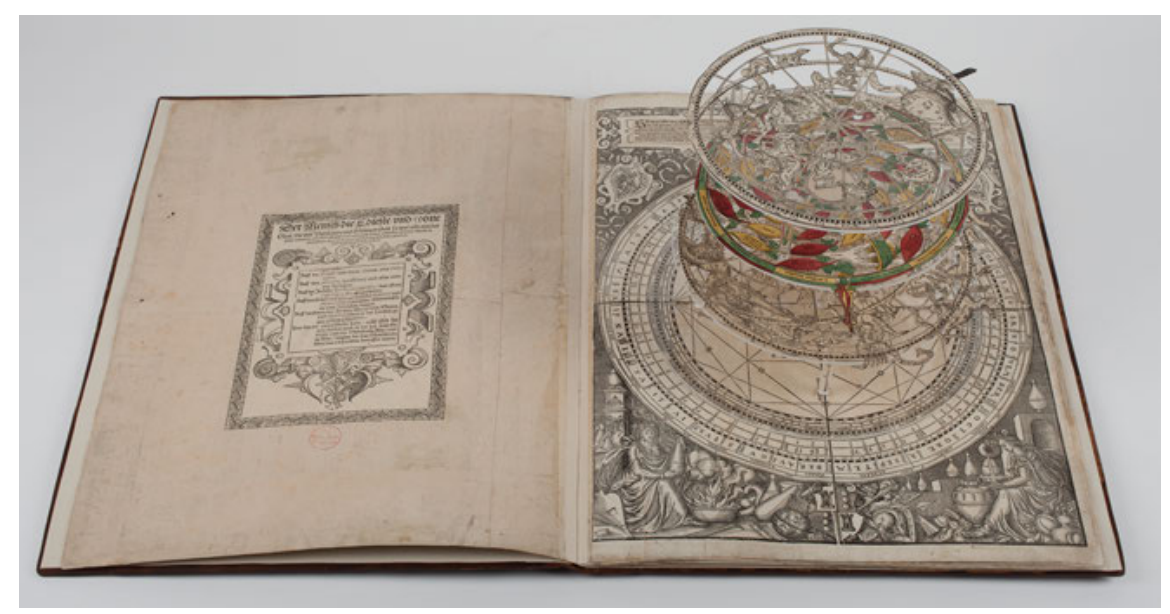

Abb. 8: Leonhard Thurneysser: Astrolabium. Berlin 1575. Konstruktionsweise, vorgeführt am Exemplar der Staatsbibliothek Berlin, Sign. Libri impr. rari fol. 641 (unter dem Titel Dess Menschen Circkel vnd Lauff katalogisiert).

Die gesamte Archidoxa, so scheint es, ist damit im Grunde nur ein Beiwerk zu dem »Astrolabium«, mit dem sich jeder Käufer sein eigenes Horoskop erstellen und die entsprechende pharmazeutische Medikation bestimmen konnte. Die Versform der Archidoxa ist ein Element, das zum repräsentativen Charakter des gesamten Werkes beitragen sollte, genauso wie auch die (gängigen und bekannten) Inhalte der Archidoxa - so paradox das klingen mag - nicht der eigentliche Zweck dieses Werkes sind. Der eigentliche Zweck der Archidoxa ist die Idee eines Buchs, das das arkane Wissen der Alchemie und das bis zu diesem

12 Vgl. ebd., S. $108 \mathrm{f}$. 


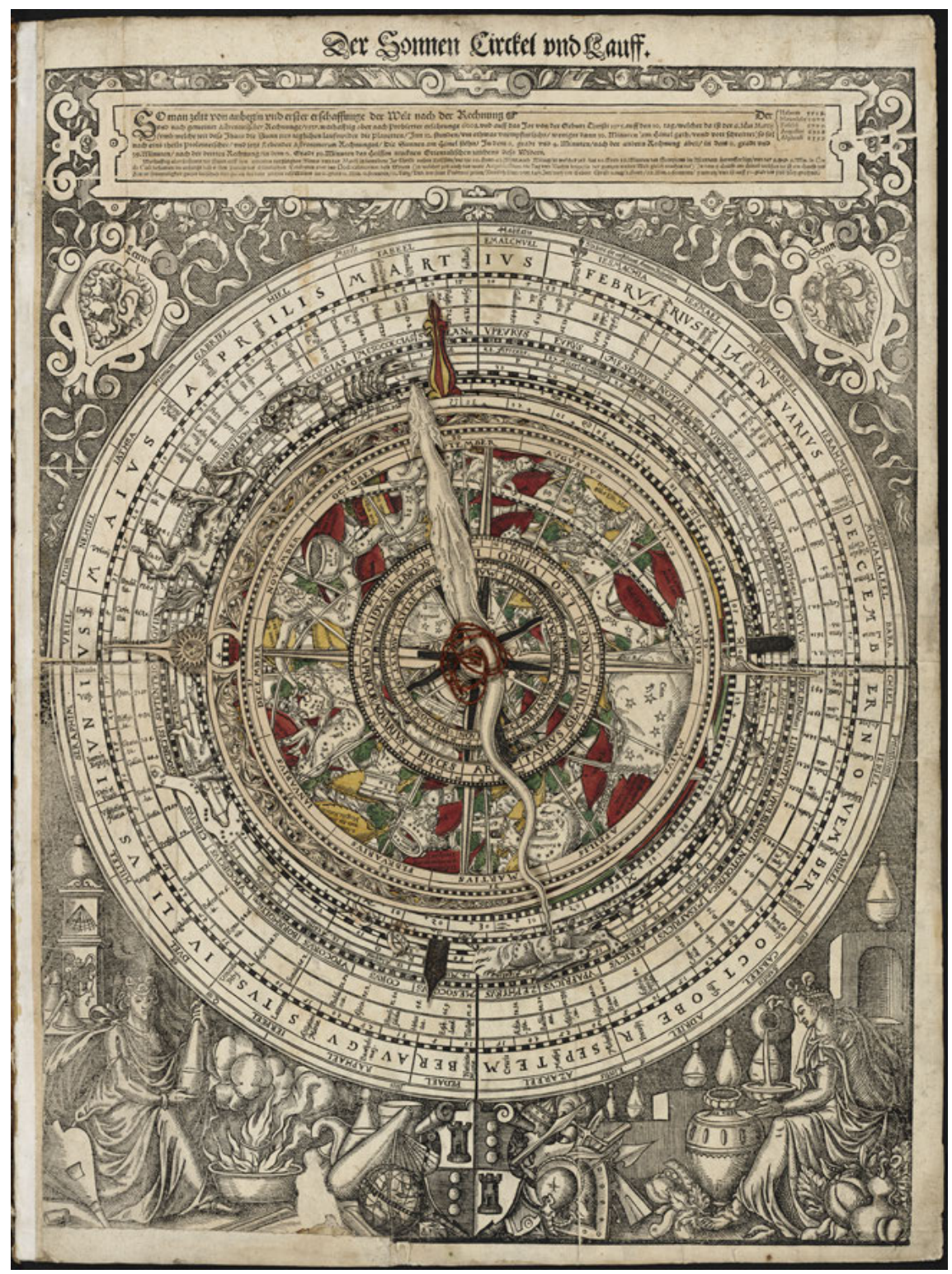

Abb. 9: Leonhard Thurneysser: Astrolabium. Berlin 1575. Konstruktionsweise, vorgeführt am Exemplar der Staatsbibliothek Berlin, Sign. Libri impr. rari fol. 641 (unter dem Titel Dess Menschen Circkel vnd Lauff katalogisiert). 
Zeitpunkt nur Spezialisten verfügbare Wissen der Astrologie allgemein auf dem Buchmarkt verfügbar macht. Es ginge Thurneysser um die Erschließung eines ökonomisch relevanten Marktsegments: Statt ein teures Horoskop bei einem Astrologen bestellen zu müssen, kann sich der Käufer der Archidoxa sein Horoskop selbst erstellen, seine astrologisch bedingten, physiologischen Schwächen herausfinden und sich dann auch (nach Konsultation der Quinta essentia) die entsprechende Diät oder Medikation verschreiben.

Die These lautet also, dass es sich bei der Archidoxa nicht um ein sliterarisches`Werk im Sinne des 18. Jahrhunderts handelt, sondern um ein höchst innovatives Druckerzeugnis, das die neuen technischen Möglichkeiten des Buchdrucks mit der Versform als Ausweis eines uralten, gelehrten und unvergänglichen Wissens und einer pseudo-arkanen, von der älteren Alchemie inspirierten Verrätselung verbindet. Diese These möchte ich im folgenden Abschnitt mit einem Blick auf Thurneyssers zweiten großen Verstext von alchemischer Seite bestätigen. In einem dritten Schritt möchte ich dann aus Thurneyssers Tätigkeit als Autor, Drucker und Verleger in Personalunion dieses damit schon skizzierte, medienhistorische Argument ableiten.

\section{Thurneyssers Quinta essentia (1570 und 1574)}

Neben der Archidoxa publiziert Thurneysser 1570 bei Ossenbrug in Münster noch eine zweite Dichtung, die Quinta essentia. ${ }^{13}$ Auch hier ist er mit der Qualität des Drucks (und insbesondere wieder der Abbildungen) unzufrieden, denn 1574 lässt er auch diesen Text ein zweites Mal erscheinen, in neuem Layout und mit neuen Holzschnitten, in Folio statt in Quarto. Diese Ausgabe druckt er allerdings nicht selbst im Grauen Kloster, sondern lässt sie bei Steinmann in Leipzig drucken vermutlich, weil die eigene Presse im Grauen Kloster ausgelastet war. Auch bei der Quinta essentia handelt es sich um ein aufwändig hergestelltes Buch, vom Papier über das Layout bis hin zu den Abbildungen, die jedes Kapitel einleiten.

Wie die Archidoxa den Anspruch erhebt, das astrologische Wissen, das durch seine Komplexität nur Spezialisten zugänglich war, öffentlich verfügbar und leicht zugänglich zu machen, so tritt die Quinta essentia mit dem Anspruch auf, das geheime Wissen der Alchemie zu enthüllen. Das erste Kapitel trägt den Titel »Die Ewige Heimligkeit redet«.

13 Vgl. die (leider allerdings nicht kritische, sprachlich modernisierte) Neuausgabe von Hofmeier: Leonhard Thurneysser. Quinta essentia 1574. Ein alchemisches Lehrbuch in Versen. Hg. von Thomas Hofmeier. Berlin, Basel 2007. 


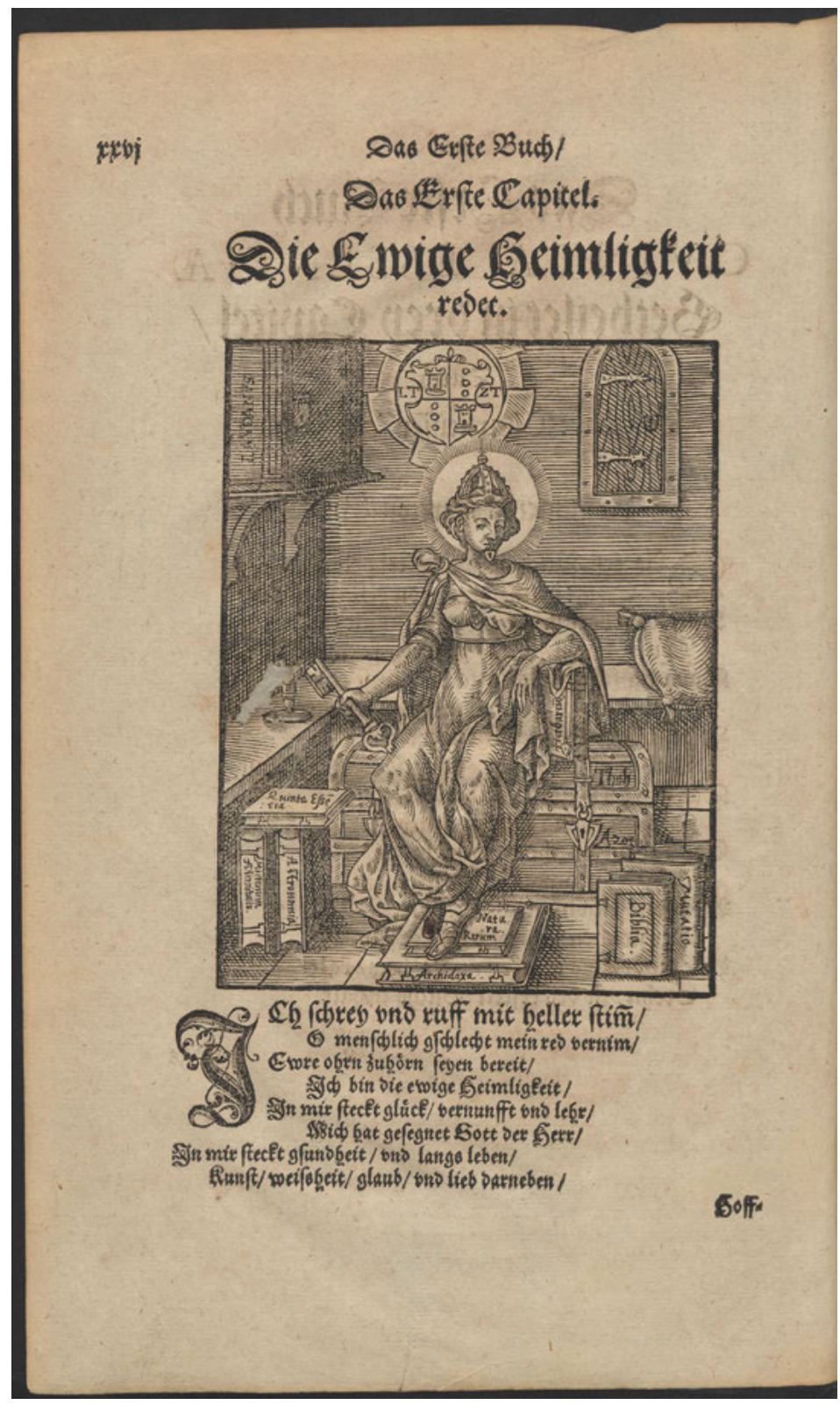

Abb. 10: Leonhard Thurneysser: Quinta essentia. Leipzig 1574, S. 26: Die Ewige Heimligkeit redet. Abbildung aus dem Exemplar der Staatsbibliothek Berlin, Sign. 4 Mu 2011a. 
Der Holzschnitt zeigt die Heimlichkeit personifiziert als weibliche Figur mit einem Schloss vor dem Mund, auf einer Truhe sitzend, zu der sie den Schlüssel in der rechten Hand hält. »Azot « und »Thoh« steht auf der Truhe, wobei es sich bei »Azot« um jenes Allheilmittel des Paracelsus handelt, das langes Leben und Gesundheit verspricht. »Laudanus« steht auf dem Schrank links oben, womit auf das später »Laudanum« genannte Opiumderivat verwiesen ist, das ebenfalls als eine Erfindung von Paracelsus galt und in der Folge zu einem der bekanntesten Pharmaka der paracelsischen Apotheke wurde. ${ }^{14}$ Unter den Füßen der "Heimligkeit« liegen De natura rerum von Paracelsus und die Archidoxa, ${ }^{15}$ links daneben die Quinta essentia, unter ihrem linken Arm das Herbarium, also die Bücher von Thurneysser selbst. Außerdem finden sich abgebildet die Bibel, ein der »Mutatio« gewidmetes Werk, eine Astronomia und ein Misterium Aeternitatis. Oberhalb der »Heimligkeit« hängt an der Wand das Wappen Thurneyssers.

Was die »Heimligkeit « im ersten Kapitel in knapp dreihundert Versen verkündet, ist (analog zur Archidoxa) der Verlust der adamitischen Weisheit mit der Vertreibung aus dem Paradies sowie deren zumindest partielle Wiederentdeckung in den folgenden Jahrhunderten. Diese Weisheit war überwiegend astro-alchemischer und pharmazeutischer Natur und wurde vor allem von einem Mann wiederentdeckt: Paracelsus. Er wurde zwar früh von Gott abberufen, aber »[s]eine schrifften ligen hie vnd dar/ | Denen man teglich starck nachtracht« (S. 34), was ein deutlicher Verweis auf die zeitgleichen Bemühungen um eine Paracelsus-Ausgabe darstellt, wie sie dann ab 1589 von Johann Huser in Basel herausgebracht wurde. ${ }^{16}$

Im zweiten Kapitel spricht die Alchemie selbst. Nach einem mehrseitigen Autorenkatalog (auch er endet mit Paracelsus als Höhepunkt) erklärt sie die verrätselte, arkansprachliche Darstellungsform des alchemischen Wissens mit der Notwendigkeit der Geheimhaltung (S. 41). Diese ist aber offensichtlich jetzt

$14 \mathrm{Zu}$ den Legenden, die sich nach dem Tod des Paracelsus um dieses Wundermittel zu ranken begangen vgl. Kühlmann/Telle: Corpus Paracelsisticum (s. Anm. 4), Bd. II.2, S. 478-483 (dort übrigens erwähnt in einem Brief von Michael Toxites an Thurneysser), sowie Joachim Telle: Theophrastus von Hohenheim - Irrlehrer oder Leitgestalt einer Alternativmedizin des 21. Jahrhunderts? In: Nova Acta Paracelsica N.F. 24/25 (2010/11), S. 17-62, hier S. 48-51. Das Titelblatt der Quinta essentia dürfte ein relativ früher Beleg für den wachsenden Ruhm dieses Medikaments sein.

15 Dabei könnte es sich sowohl um Thurneyssers Buch wie um das gleichnamige, 1569 zuerst erschienene, Paracelsus zugeschriebene Werk handeln, vgl. oben s. Anm. 4.

16 Grundlegend zur Entstehung des frühneuzeitlichen Paracelsismus ist das Corpus Paracelsisticum (s. Anm. 4). Dokumente frühneuzeitlicher Naturphilosophie in Deutschland. Hg. u. erl. v. Wilhelm Kühlmann, Joachim Telle. Tübingen $2001 \mathrm{ff}$. Vgl. insb. dort die Einleitung zum ersten Band zur Entstehung der Paracelsus-Ausgabe Husers. 
nicht mehr gegeben, denn gleich in den folgenden Versen führt die Alchemie die Erfolglosigkeit der meisten Alchemiker auf technische Fehler zurück (falsche Mengenangaben, falsche Ausgangsmaterialien, unsaubere Durchführung der Prozesse usw.). Gefordert wird damit genau die Aufhebung der »Heimligkeit«, die die Quinta essentia selbst zu leisten verspricht. Die restlichen drei Kapitel des ersten Buchs sind einer schematischen Gegenüberstellung der alten und neuen Medikamente gewidmet. Auf der einen Seite stehen die salten`, galenischen Medikamente (also die akademische `Schulmedizin`), auf der anderen Seite die sneuen`, chemisch präparierten Medikamente, jeweils gegliedert nach Anwendungsgebieten. Indem Thurneysser keine Angaben zur Herstellung dieser Medikamente macht, ${ }^{17}$ geht es ihm wohl eher darum, einen Index zu erstellen, der aufzeigt, über welche Therapiemöglichkeiten die neue, paracelsische Medizin verfügt.

Das zweite Buch der Quinta essentia entwickelt eine Art anthropologische Grundlage für die Behandlung mit den neuen Medikamenten, indem es die vier Teile des Menschen erläutert: Geist, Seele, Körper und Gemüt. ${ }^{18}$ Das dritte Buch führt in die (al)chemische Praxis, indem es lehrt, wie die vier Elemente - Wasser, Erde, Feuer, Luft - im Labor getrennt werden können. Das vierte Buch ist Quecksilber-Produkten gewidmet, das fünfte Buch metallischen Turbiten, das sechste Buch mineralischen Tinkturen, das siebte Buch den Schwefeln, das achte Buch den Salzen, das neunte den Ölen und Essenzen, das zehnte Buch den Qualitäten der Mineralien und Metallen (Quecksilber, Vitriol, Arsen, Salz usw.). Das elfte und zwölfte Buch gelten der Zubereitung des Steins der Weisen, wobei Thurneysser signifikanter Weise an diesem Punkt der Quinta essentia die verrätselte (Zahlen- und Buchstabenrätsel), arkansprachliche Darstellungsform der älteren Alchemie aufgreift, sowohl im Text, wie in den Abbildungen. Während die Abbildungen bis zu diesem Punkt sachlich-illustrativen Charakter hatten, sind die Abbildungen zu den letzten drei Kapiteln emblematisch-rätselhafte Darstellungen bestimmter Verfahren, wie z. B. der getötete Drache, dessen Blut in ein Grab läuft.

Die Überzeugung von der Existenz und Möglichkeit eines Steins der Weisen sollte allerdings nicht dazu verführen, Thurneysser wahlweise zu einem Betrüger, Scharlatan oder Spiritualisten zu erklären. Interessanterweise sind das elfte und zwölfte Buch der Quinta essentia nämlich nicht die einzigen Schriften, in der Thurneysser die Herstellung des Steins der Weisen beschreibt. An der

17 Im Unterschied zur späteren Magna Alchymia, vgl. den Befund von Bosch und Morys, unten s. Anm. 25.

18 Diese Vierteilung ist eine Abweichung von der paracelsischen Medizin, die nur die ersten drei Teile kennt. 


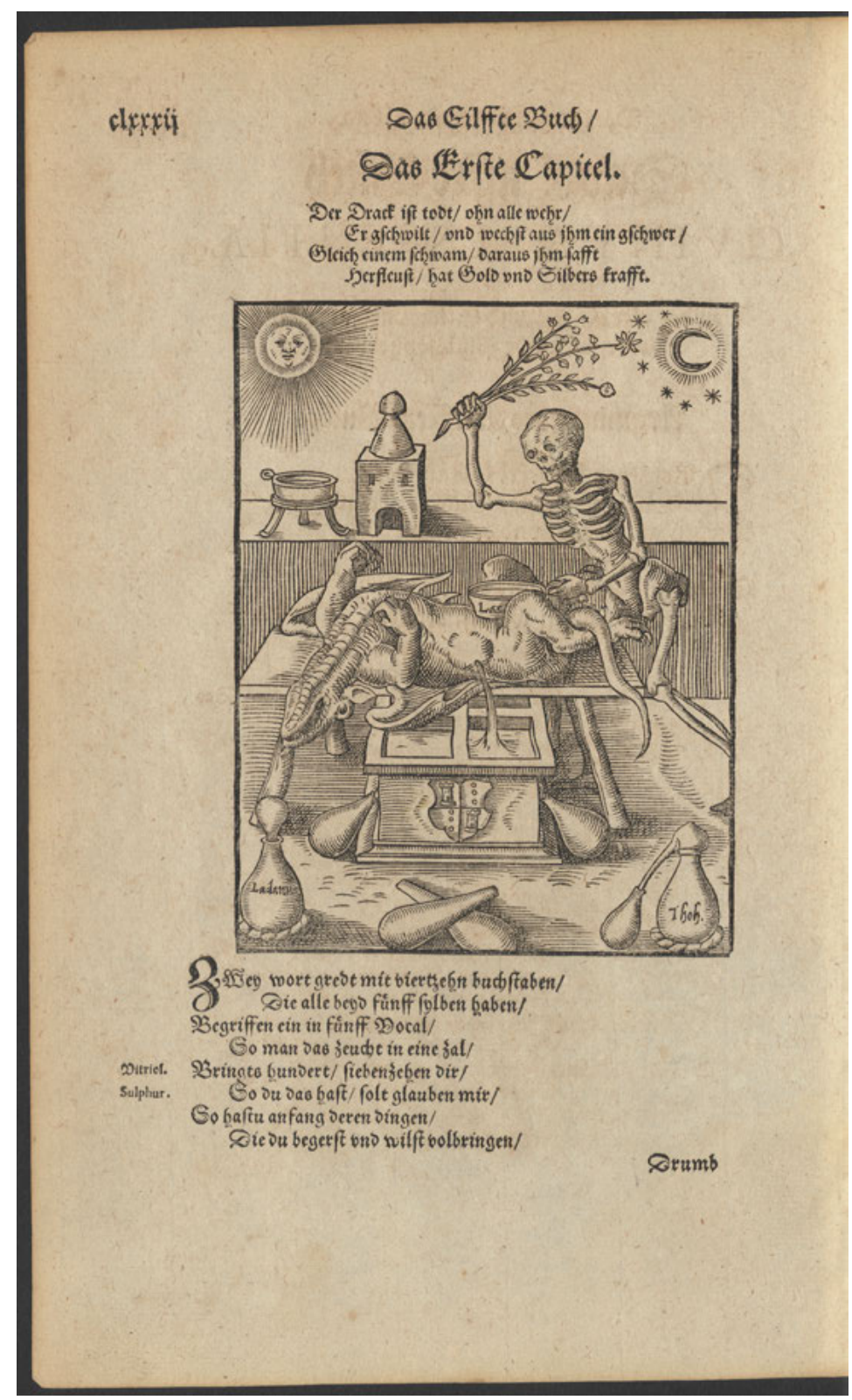

Abb. 11: Leonhard Thurneysser: Quinta essentia. Leipzig 1674, S. 128. Abbildung aus dem Exemplar der Staatsbibliothek Berlin, Sign. $4^{\circ} \mathrm{Mu} 2011 \mathrm{a}$. 
Staatsbibliothek Berlin ist ein Manuskript mit dem Titel De transmutatione veneris in solem erhalten, in dem Thurneysser einen sehr konkreten, labortechnisch umsetzbaren Prozess zur Herstellung des Steins der Weisen beschreibt. ${ }^{19}$ Anders als in der Quinta essentia bedient Thurneysser sich hier auch nicht der Arkansprache, sondern beschreibt den Prozess aperte, inklusive illustrierender Abbildungen. Zumindest dieser letzte Punkt dürfte darauf zurückzuführen sein, dass die Handschrift unmittelbar an den brandenburgischen Kurfürsten gerichtet ist, den Thurneysser im Grunde aber eher vor dem Versuch warnt, den beschriebenen Prozess tatsächlich zu erproben. Thurneysser äußert sich nämlich gleich zu Beginn kritisch über die Möglichkeit, den Stein herzustellen - und zwar nicht, weil es unmöglich sei, sondern weil der Prozess sehr aufwändig, kostspielig und kompliziert sei (er zieht sich insgesamt über ein Jahr hin). Da das Ergebnis außerdem vor allem von dem Zustand der verwendeten Erze abhängig sei, warnt Thurneysser den Kurfürsten vor größeren finanziellen Einbußen. Er selbst könne dieses unternehmerische Risiko nicht tragen und fordert deshalb - wenn der Kurfürst auf der Durchführung des Versuchs bestünde - eine Verzinsung von jährlich 500 Thalern auf die von ihm für den Prozess aufzuwendende Summe, die er konkret mit 10000 Thalern angibt.

Wenn man will, kann man auch hier wieder den Scharlatan und Betrüger Thurneysser am Werk sehen, der aus allem Geld macht - wie so viele (Al)Chemiker der Frühen Neuzeit, die wahlweise reich geworden oder ihr Leben verloren haben, indem sie den Fürsten versprachen, Gold machen zu können. Man könnte aber gerade aus den konkreten, sowohl finanziellen wie metallurgischen Angaben der Handschrift auch den Schluss ziehen, dass Thurneysser von der theoretischen Möglichkeit, den Stein der Weisen herzustellen, überzeugt war, genauso aber eben von der technischen Schwierigkeit. Auch etwa Andreas Libavius, der in seiner Alchemia eine durchaus technische (Al)Chemie beschreibt und über den Vorwurf der Betrügerei und Scharlatanerie erhaben ist, ist fest von der Möglichkeit eines solchen Steins überzeugt. In der Tat dürfte die grundlegende, chemische Erfahrung, dass es möglich war, aus Kupfer und Zinn die höherwertige Bronze herzustellen oder aus Sand und Pottasche Glas zu schmelzen, die Möglichkeit einer Transmutation als solcher gerade für die Praktiker außer Frage gestellt haben - jedenfalls für jeden, der, wie Thurneysser, jahrelang in den Bergwerken Tirols gearbeitet hatte, der am Schmelzoffen gestanden und die Verwandlung der Elemente hatte beobachten können. In die-

19 Ich stütze mich im Folgenden ausschließlich auf die Darstellung von Peter Morys: Leonhard Thurneissers De transmutatione veneris in solem. In: Christoph Meinel (Hg.): Die Alchemie in der europäischen Kultur- und Wissenschaftsgeschichte. Wiesbaden 1986, S. 85-98. 
sem Sinne dürfte es auch zu verstehen sein, wenn Thurneysser gleichzeitig in der Magna Alchymia schreibt, ${ }^{20}$ er hätte noch niemanden gesehen, der Gold herstellen könne. Denn auch das kann eben heißen, dass der Prozess so aufwändig und kompliziert ist, dass er in der Praxis nicht gelingt. Vor allem aber distanziert sich Thurneysser an dieser Stelle von allen, die die (Al)Chemie auf die Herstellung von Gold und Silber beschränken wollen. Auch in diesem Punkt schließt er eng an Paracelsus an, der das >Goldmachen`scharf abgelehnt hat, ohne seine Möglichkeit zu bestreiten. ${ }^{21}$

Auf der anderen Seite muss man im Blick behalten, dass Thurneysser als junger Mann Basel hatte verlassen müssen, weil er einem Juden, bei dem er verschuldet war, mit Gold überzogenes Blei verpfändet hatte, wofür er sich noch 1584 in seinem Notgedrungenen Ausschreiben rechtfertigen zu müssen glaubt. ${ }^{22}$ Und noch 1586 hat er in Rom einen Nagel in Gold verwandelt, was - außer dem Großherzog von Florenz, der den Nagel in seiner Kunstkammer ausstellte schon in der Zeit niemand geglaubt hat. ${ }^{23}$ Thurneysser ist ohne Frage eine höchst ambivalente, schwierig zu fassende Persönlichkeit.

Das letzte, dreizehnte Buch der Quinta essentia bietet schließlich eine Selbstreflexion Thurneyssers, »warumb diese Bücher gschrieben « (S. 199). Ein Grund dafür ist die - auf den ersten Blick für das Jahr 1570 vielleicht erstaunliche - Behauptung, dass gerade jeder ein Paracelsist sein wolle, »ohn allen verstand« (S. 202). Paracelsus selbst sei »alles lobs würdig«, aber was derzeit unter seinem Namen verkauft werde, habe nicht viel mit ihm zu tun. Paracelsus habe das Handwerk der Destillation (also die grundlegende chemische Technik in der Zubereitung von Pharmaka) zu einem unerreichten Höhepunkt geführt. »Ohn einige andere substantz/ | Rein/ durchleucht/ klar/ vnd subtil gantz« habe er seine Essenzen extrahiert und »durch solche krafft « »wunder « geschaffen (S. 203). Seine Jünger dagegen würden seinem Namen Schande machen, weil sie nicht ordentlich »ausziehen « und »scheiden « könnten, also eben die chemischen Techniken nicht beherrschten.

20 Leonhard Thurneysser zum Thurn: Magna Alchymia. Cölln 1587, S. 2.

21 Vgl. Joachim Telle: Paracelsus als Alchemiker. In: Heinz Dopsch, Peter F. Kramml (Hg.): Paracelsus und Salzburg. Salzburg 1994, S. 157-192. Vgl. allerdings jetzt die Präzisierungen von Andrew Sparling: Paracelsus, a Transmutational Alchemist. In: Ambix 67,1 (2020), S. 62-87.

22 Leonhard Thurneysser: Ein Durch Noth gedrungens Außschreiben. Berlin 1584 (Erster Teil: Protestatio), S. VIII f., Marginalie.

23 Vgl. den für diese Art von Legenden grundlegenden Artikel von Didier Kahn: The Significance of Transmutation in Early Modern Alchemy. The Case of Thurneysser's Half-Gold Nail. In: Marco Beretta, Maria Conforti (Hg.): Fakes!? Hoaxes, Counterfeits and Deception in Early Modern Science. Sagamore Beach 2014, S. 35-68. 
Ein weiterer Grund für die Abfassung der Quinta essentia sei der »jemmerliche« Zustand der Pharmazie. Damit meint Thurneysser sowohl die Apotheken, die "visitiert" - also überprüft - werden müssten, weil sie einem alles Mögliche verkauften, ohne dass man sich auf die Qualität und behauptete Herkunft der Stoffe verlassen könne (S. 204). Die Ärzte ihrerseits würden ihren Patienten die aus diesen Stoffen hergestellten Pharmaka dann einflößen, ohne sie vorher kontrolliert zu haben. Die pharmazeutischen Substanzen dürften nicht einfach nach Rezepten zusammengemischt werden, die man seit der Antike immer wieder abgeschrieben habe. Rezepte müssen empirisch überprüft werden, schon, weil es einen erheblichen Unterschied mache, aus welcher geographischen Region die jeweiligen Kräuter und Pflanzen stammten. Grundsätzlich sei die »alte Artzeney«, also die aus der Antike stammenden, aus pflanzlichen Stoffen hergestellten Pharmazeutika, weitaus weniger wirksam als die neuen, »aus Minerischen sachen« hergestellten Pharmazeutika (S. 209). Die Kräuterheilkunde der Antike sei zwar nicht zu verachten, leide aber darunter, dass sie nicht einfach auf eine andere Zeit, eine andere Region und andere Menschen übertragbar sei. Metalle dagegen seien »aller orten gleich" und hätten eine "grösser würckung" »denn alle andre ding auff Erdt« (S. 209).

Nach der Lektüre der Quinta essentia sollte jedem zeitgenössischen Leser klar gewesen sein, dass es sich bei Thurneysser um einen überzeugten Paracelsisten handelte. Anders aber als etwa bei Alexander von Suchten, Benedict Figulus ${ }^{24}$ oder Heinrich Khunrath, deren Paracelsismus viel stärker ein metaphysisches, theoalchemisch-spiritualistisches Konstrukt darstellt, äußert sich der Paracelsismus Thurneyssers sehr konkret in der Berufung auf bestimmte pharmazeutische Substanzen und (al)chemische Herstellungsprozesse. Zumindest in diesem Punkt nimmt er Oswald Crolls Basilica chymica (1609) vorweg, bei der es sich im Kern um eine Rezeptsammlung handelt, also um einen weiteren Versuch, die praktische Relevanz des Paracelsismus, seine medizinisch-pharmazeutische Bedeutung für die ärztliche Praxis zu erweisen. Das Urteil über die Qualität der Rezepte Thurneyssers, zu dem der Pharmaziehistoriker Klaus Bosch gekommen ist, bestätigt diese Behauptung:

24 Von Benedict Figulus wurde Thurneysser seine >Vermarktung` der paracelsistischen Alchemie zum Vorwurf gemacht. Im Vorwort zu seiner Pandora magnalium naturalium aurea et benedicta, Straßburg 1608, f. ${ }^{\star \star} 6^{\mathrm{v}}$, bezichtigt Figulus Thurneysser einer »falschen Alchymey« und wirft ihm »Mercketenterey/ vnnd Kauffmanschafft « mit den paracelsischen Geheimnissen vor. Vgl. den Hinweis auf diese Stelle von Joachim Telle in Corpus Paracelsisticum (s. Anm. 4), S. 438 . 
Obwohl Thurneysser seine medizinischen Schriften teilweise schwer verständlich, durchzogen von Gleichnissen aus Astrologie und Alchemie, abfaßte, sind die darin enthaltenen Vorschriften erstaunlich gut: 21 der 26 untersuchten Rezepte sind deutlich, 5 Vorschriften sind z. T. deutlich. Wohl auf Grund seiner eigenen Erfahrung auf dem Gebiet der Chemie war er bemüht, seine Rezepte praktischen Erfordernissen anzupassen. ${ }^{25}$

In der Zahl der Rezepte, die erstmalig bei Thurneysser nachzuweisen sind, übertreffe Thurneysser alle seine Vorgänger, ausgenommen Paracelsus. Diesem Urteil hat sich auch Peter Morys angeschlossen. Er charakterisiert die pharmazeutischen Anweisungen Thurneyssers geradezu als vorbildlich für ihre Zeit:

Die von ihm verwendeten Substanzen sind zwar weitgehend die auch in der Alchemie seiner Zeit gebräuchlichen Stoffe, die beschriebenen Verfahren sowie die Mengenangaben lassen jedoch den Stil klarer, gut verständlicher Laboranleitungen erkennen. Vorschriften, die in einer schwer verständlichen Sprache und verschlüsselt gehalten sind, werden durch Marginalien erklärt, so daß Thurneisser damit nicht den Zweck der alchemistischen Arkansprache beabsichtigt haben kann, er will vielmehr den Leser lediglich zum Nachdenken anregen. ${ }^{26}$

Die alchemische Bildwelt diene, wo sie zur Anwendung komme, ausschließlich zur Beschreibung chemischer Vorgänge. „Die deutliche Diktion der Rezepte, die durchaus mit neuzeitlichen chemischen Vorschriften verglichen werden können, zeigt, daß Thurneisser an deren praktischer Verwendbarkeit viel gelegen war. ${ }^{27}$

Unabhängig von den konkreten Rezepten bietet Thurneysser 1570 mit der Quinta essentia aber auch den frühen Versuch einer Systematisierung der paracelsischen Lehren. Gerhard Dorns Clavis totius Philosophiae Chymisticae, der als erster Versuch einer solchen Systematisierung gilt, war erst 1567 im Druck erschienen, die deutsche Fassung erst 1602, so dass Thurneysser ihn nicht gekannt haben dürfte. ${ }^{28}$ Die eigentliche Welle des Paracelsismus hebt erst nach

25 Klaus Bosch: Zur Vorgeschichte chemiatrischer Pharmakopöepräparate im 16./17. Jahrhundert. Braunschweig 1980, S. 28.

26 Peter Morys: Medizin und Pharmazie in der Kosmologie Leonhard Thurneissers zum Thurn (1531-1596). Husum 1982, S. 47, der sich dort seinerseits auf die Studie von Bosch bezieht. Die folgende Zusammenfassung der (al)chemischen Grundlagen von Thurneyssers Denken ist der Darstellung von Morys verpflichtet. Rudolf Schmitz: Medizin und Pharmazie in der Kosmologie Leonhard Thurneyssers zum Thurn. In: Zwischen Wahn, Glaube und Wissenschaft. Magie, Astrologie, Alchemie und Wissenschaftsgeschichte. Hg. von Jean-Francois Bergier. Zürich 1988, S. 141-166 bietet eine präzise Zusammenfassung der Ergebnisse von Morys.

27 Morys: Medizin und Pharmazie (s. Anm. 26), S. 53.

28 Didier Kahn: Le debuts de Gerard Dorn d'apres le manuscrit autographe de sa »Clavis totius Philosophiae Chymisticae« (1565). In: Joachim Telle (Hg.): Analecta Paracelsica. Stuttgart 1994, S. 59-126, umfassend ders.: Alchimie et paracelsisme en France à la fin de la Renaissance (15671625). Genf 2007. Außerdem natürlich die Dokumentation im »Corpus Paracelsisticum«, Teil 1: Der Frühparacelsismus (s. Anm. 4). 
1570 an. Thurneysser jedoch formuliert die >chemische Philosophie celsismus in der Quinta essentia schon sehr präzise, wenn Sulphur, Mercurius und Sal (die stria prima`) mit den Prinzipien Spiritus, Anima und Corpus identifiziert werden. Sulphur und Spiritus vertreten dabei das Brennbar-Ölige, Mercurius und Anima das Flüssige und Verdampfende oder Rauchende; Sal und Corpus das Körperlich-Feste. Diese drei Prinzipien sind nicht nur in jedem chemischen Prozess vertreten, sondern bilden grundsätzlich die Prinzipien der Natur. Diese chemische Deutung der Schöpfung, des Makrokosmos wie des Mikrokosmos des menschlichen Körpers, bildet den Kerngedanken des Paracelsismus überhaupt. Die chemisch verfahrende Pharmazeutik des Paracelsismus erklärt sich aus diesem Kern, insofern jede Therapie mit diesen drei Elementen rechnen muss. Der Spiritus als das selbst formlose, aber formgebende Prinzip kann durch (al)chemische Prozesse (vor allem Destillation) aus allen Dingen extrahiert und dann in der Gestalt von Pharmaka auf den menschlichen Körper übertragen werden. Die >Kräfteく eines Minerals oder einer Pflanze, ihr Arkanum, kann sspirituell ' gelöst werden und dann seine Wirkung im menschlichen Körper entfalten. Der Anima dagegen kommt bei Prozessen des Verflüssigens und Auflösens entscheidende Bedeutung zu, dem Corpus bei Prozessen der Verfestigung und >Verkörperung`. Analog dazu entstehen Krankheiten, indem sich die natürliche Feuchte im Körper erhöht, Dünste entstehen oder sich Stoffe ablagern, also verfestigen. Physiologische Prozesse werden damit chemisch gedacht. Was der Magen innerhalb des Körpers leistet, wenn er Substanzen in ihre Bestandteile zerlegt, leistet das Feuer bei der Zubereitung von Speisen oder der Apotheker, wenn er aus Substanzen ihre `Subtilitäten` extrahiert. Erkrankungen, die durch das Prinzip des Sal verursacht sind, müssen deshalb durch Pharmaka kuriert werden, die dieses Prinzip wieder ins Gleichgewicht bringen, etwa indem Nierensteine (die als salische Ablagerungen gedacht wurden) wieder aufgelöst und verflüssigt werden.

\section{Thurneysser als (al)chemisch-pharmazeutischer Unternehmer}

Die damit implizierte, grundsätzliche Analogie von organischen und anorganischen Prozessen, von Mikro- und Makrokosmos spiegelt sich im Werk Thurneyssers insofern, als der Quinta essentia 1583 als zweite große (al)chemische Schrift die Magna Alchymia an die Seite tritt. Ihr Titel lautet: 
МЕГААН ХYMIA, vel Magna Alchymia. Das ist ein Lehr vnd vnterweisung von den offenbaren vnd verborgenlichen Naturen/ Arten vnd Eigenschafften/ allerhandt wunderlicher Erdtgewechssen/ als Ertzen/ Metallen/ Mineren/ Erdsäfften/ Schwefeln/ Mercurien, Saltzen vnd Gesteinen.

Thurneysser geht in diesem (nun in Prosa verfassten) Werk noch erheblich systematischer vor. Das erste Buch ist dem Schwefel gewidmet, das zweite den Salzen, das dritte dem Salarmoniac (Salmiak), das vierte dem Alaun, das fünfte dem Salpeter, das sechste dem Quecksilber. Mit dem siebten Buch wendet sich Thurneysser den astrologischen Einflüssen auf diese Stoffe zu, mit dem achten den geographischen. Auch hier werden astrologische Einflüsse wieder selbstverständlich als natürliche Einflüsse behandelt. Das neunte Buch gilt den Schmelztechniken und Metallarbeiten. Die Herkunftsbeschreibungen, die Rezepte und Anweisungen sind höchst präzise und immer wieder mit empirischen Beobachtungen durchsetzt. Wir haben es mit einem Werk zu tun, das zwar im Titel noch »Alchemie« heißt, von seinen Inhalten her aber in die Geschichte der Metallurgie, der Ingenieurwissenschaft, der Materialkunde und der Geologie gehört. Die Tatsache, dass der gelernte Goldschmied Thurneysser in der ersten Hälfte seines Lebens ein Bergwerk in Tirol geleitet hatte - wo er unter anderem eine Schmelz- und Schwefelhütte angelegt hatte - und dann von Erzherzog Ferdinand II. von Österreich ausdrücklich auf Reisen geschickt worden war, um seine Kenntnisse in Bergbau und Metallverarbeitung zu verbessern, macht sich hier deutlich bemerkbar. Die Magna Alchymia kündet von den praktischen Erfahrungen, die Thurneysser auf diesen Reisen gesammelt hat. ${ }^{29}$

Einen ähnlichen Befund ergibt der Blick in das Werk, mit dem 1572 die Karriere Thurneyssers am Brandenburger Hof begann: Pison, Das erst Theil. Von Kalten/ Warmen/ Minerischen vnd Metallischen Wassern/ sampt der vergleichung der Plantarum vnd Erdgewechsen. Das Werk - ursprünglich auf vier, ganz Europa umspannende Bände angelegt, die allerdings nie erschienen sind - bietet auf 420 Seiten eine detaillierte Beschreibung der deutschen Gewässer und ihres jeweiligen Mineralgehalts sowie deren pharmazeutischer Wirkung, durch umfangreiche Register erschlossen. Es handelt sich um eine ungeheure Masse von geographischem, mineralogischem, limnologischem, botanischem und allgemein naturkundlichem Wissen, das Thurneysser zum Teil tatsächlich auf seinen eigenen, ausgedehnten Reisen gesammelt hat, zum Teil wohl sich hat berichten lassen, zum Teil aus Reiseberichten und älterer Literatur zusammengeschrieben hat.

$29 \mathrm{Zu}$ Thurneyssers Selbststilisierung als Reisender und seinen behaupteten Sprachkenntnissen vgl. allerdings die Vorbehalte von Tobias Bulang: Die Welterfahrung des Autodidakten. Fremde Länder und Sprachen in den Büchern Leonhard Thurneyssers zum Thurn. In: Daphnis 45 (2017), S. 510-537. 
Das erste Buch formuliert eine Theorie, »woher die Wasser ihr Metallische vnd Minerische krafft empfahen«, im zweiten Buch stellt Thurneysser die Instrumente vor, die er zum »Probieren« des Wassers - für die chemische Analyse - entwickelt hat, das dritte Buch behandelt Möglichkeiten, künstliche Mineralwässer herzustellen (also Wasser mineralisch anzureichern), im vierten Buch gibt Thurneysser Anweisungen für die Einrichtung »künstlicher Bäder« und die pharmazeutische Wirkung der jeweiligen Mineralien, mit denen diese Bäder angereichert werden können. Mit dem fünften, der Donau und ihren Zuflüssen gewidmeten Buch wendet Thurneysser sich dann der Geographie und Limnologie zu. Das sechste Buch gilt dem Rhein und seinen Zuflüssen, das siebte der Elbe, das achte der Ems, das neunte der Weser und das zehnte der Oder.

Das Prinzip, das Thurneysser in diesem Werk für die Analyse des mineralischen Gehaltes von Wasser entwickelt, ist im Kern noch heute gültig: Thurneysser lässt eine Wasserprobe verdampfen, glüht die Rückstände und zieht aus der Färbung der Flamme Rückschlüsse auf die vorhandenen Substanzen. Detailliert werden die dafür notwendigen Instrumente beschrieben und abgebildet. Im zweiten Teil des Buchs, der den deutschen Gewässern gewidmet ist, werden die Ergebnisse dieser Mineralanalyse für jeden Fluss einzeln dargestellt. ${ }^{30}$ Diese Ergebnisse setzt Thurneysser dann wiederum in Bezug zu den Pflanzen, die an diesen Flüssen wachsen, was natürlich Einfluss auf deren pharmazeutische Wirkung hat. ${ }^{31}$ Auch das ist eine Beobachtung, deren Bedeutung heute niemand mehr in Frage stellen kann: Die mineralische Zusammensetzung von Gewässern und Böden ist dafür verantwortlich, welche Pflanzen dort jeweils wachsen und wie sie sich entwickeln.

Ihre praktische Anwendbarkeit hat auch eine Destilliermethode für Erdöl bewiesen, die Thurneysser entwickelt hat. Als Johann Theophil Hoeffel 1734 anlässlich der Erdölquelle im elsässischen Pechelsbronn die erste wissenschaftliche Abhandlung über den therapeutischen Nutzen von Erdöl verfasste, stellte er fest, dass sich die von Thurneysser beschriebene Methode zur Verbesserung

30 Gernot Rath: Die Anfänge der Mineralquellenanalyse. In: Medizinische Monatsschrift 3 (1949), S. 539-541 sieht in Thurneysser den Begründer einer quantitativen, chemischen Analyse, während Paracelsus über »spekulative Ausdeutungen« nicht hinausgekommen sei (ebd., S. 540). Während Rath zu einem äußerst positiven Urteil über das von Thurneysser entwickelte Verfahren kommt, bezeichnet er die konkreten Resultate einzelner Analysen als »nicht haltbar« und »reine Hypothesen« (ebd., S. 540). Gernot Rath: Die Mineralquellenanalyse im 17. Jahrhundert. In: Sudhoffs Archiv 41 (1957), S. 1-9 zeigt, dass Andreas Libavius das Verfahren Thurneyssers übernimmt. Allen G. Debus: The Chemical Philosophy. New York 1977, Bd. 1, S. 109-112 fasst die Ergebnisse Raths zusammen.

31 Leonhard Thurneysser: Pison. Frankfurt a.d.O. 1572, f. $\mathrm{xx}^{\mathrm{r}}$. 
der Eigenschaften von Bitumen am besten eignete. ${ }^{32}$ Auch das soll hier wieder nur belegen, dass es sich zu einfach macht, wer Thurneysser als Scharlatan abtut. Aber selbst wenn man von solchen Einzelbefunden absieht: Im Grunde zeigt schon der flüchtige Blick in Pison, dass es sich um den Erfahrungsbericht eines Forschungsreisenden und Praktikers handelt, eines analytischen Chemikers und Limnologen avant la lettre. Es ist in der Tat nur als Rufschädigung zu bezeichnen, ${ }^{33}$ wenn ausgerechnet die Tatsache, dass Thurneysser in diesem Werk auch behauptet hat, dass die Spree Gold führe, immer wieder in den populären Darstellungen zitiert wird, um Thurneysser als Scharlatan darstellen zu können - während der ganze Rest dieses umfangreichen Werkes, das immerhin Thurneyssers Karriere begründet hat, praktisch keine Beachtung gefunden hat.

In der Vorrede $\mathrm{zu}$ diesem Werk wird außerdem schon deutlich, worin die Verbindung zu zwei anderen, ebenfalls äußerst erfolgreichen Werken Thur-

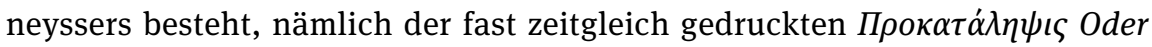
Praeoccupatio, Durch zwölff verscheidenlicher Tractaten gemachter Harm [sic!] Proben (Frankfurt/Oder 1571) und der

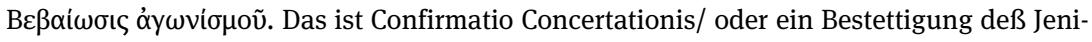
gen so Streittig/ häderig/ oder Zenckisch ist/ wie dann auß unverstandt die Neuwe und vor unerhörte erfindung der aller Nützlichesten und Menschlichem geschlecht der Notturftigesten kunst deß Harnprobirens ein zeitlang gewest ist. (Berlin 1576)
}

Die »unerhörte Erfindung «, deren sich Thurneysser hier im Titel rühmt, ist eine neue Technik der Harnprobenanalyse. Ihre Verbindung zur Mineralwasseranalyse stellt Thurneysser in der Vorrede zu Pison selbst her. Wie es nämlich »augenscheinlich« sei, dass man an den »wasserflüßlein/ so aus dem aller tiefesten gebirg « entsprängen, erkennen könne, aus welchen Metallen und Gesteinen dieses Gebirge gebildet sei, so könne man am Harn des Menschen »die Wurtzel der gründ vnd vrsprüng/ aller im geblüt liegenden gepresten « erkennen. »Dann dis ist einmal gewis/ das die wasser der Metallen/ die Harn aber der Morborum arten in jnen subtiler weis/ vnd geistlich in sich füren/ von denen sie (wie hernach folgt) ihren vrsprung nemen. « Dass ausgerechnet ihm diese Entdeckung gelungen sei, führt Thurneysser auf seine mehrfache Qualifikation sowohl als Bergwerksingenieur wie als Anatom und Chemiker zurück, wobei seine anato-

32 Jean Theophile Hoeffel: Historica Balsami Mineralis Alsatici sev Petrolei Vallis Sancti Lamperti. Der Hanauische Erdbalsam/ Lampertslocher Oel- oder Bächelbrunn. Straßburg 1734. Teilabdruck in Alfred Scheld: Erdöl im Elsass. Die Anfänge der Ölquellen von Pechelbronn. Ubstadt-Weiher 2012. Zu Thurneyssers Methode dort S. 60.

33 So der Titel des Büchleins von Thomas Hofmeier: Rufschädigung. Leonhard Thurneysser. 1531-1596. Berlin, Basel 2012. 
mische Erfahrung auf den Leichen beruhe, die er in seiner Zeit als Soldat auf den Schlachtfeldern »anathomieret vnd durchsehen « (Vorrede f. $\mathrm{x} 5^{\mathrm{v}}$ ) habe.

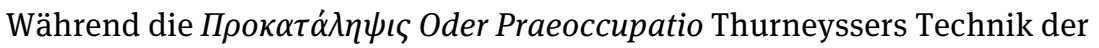
Harnprobenanalyse an zwölf Beispielen exemplarisch vorführt, liefert die $B \varepsilon \beta \alpha i \omega$ oı $\dot{\alpha} y \omega v i \sigma \mu o \tilde{.}$. Das ist Confirmatio Concertationis eine technisch-theoretische Erklärung dieser Methode, auch hier wieder mit einer detaillierten Beschreibung der zur Anwendung kommenden Instrumente, einschließlich der Darstellung eines von Thurneysser selbst entworfenen, ausschließlich der Harnprobenanalyse dienenden Ofens (drucktechnisch innovativ dargestellt durch aufklappbare Abbildungen, die das Innere des Ofens zeigen). Thurneyssers Technik der Harnprobenanalyse beruht dabei auf derselben Methode wie seine Analyse des mineralischen Gehaltes von Gewässern - was voraussetzt, dass der menschliche Körper analog zur anorganischen Natur gedacht wird: Wie die Gewässer durch ihren Mineralgehalt die Zusammensetzung des Erdinneren zu erkennen geben, so kann man am mineralischen Gehalt des Urins den Zustand des menschlichen Körpers erkennen. Zwar begründet Thurneysser seine neue Analysemethode spekulativ (mit der tria prima-Lehre des Paracelsus, der Analogie von Mikro- und Makrokosmos usw.), aber mit dem Grundgedanken, die Harnschau nicht nur auf Geruch- und Geschmacksproben zu beschränken (wie seit der Antike praktiziert), sondern den Harn einer chemischen Analyse zu unterziehen, betritt Thurneysser Neuland. Thurneysser unternimmt »als erster den Versuch, mit Hilfe eines chemischen Destillationsverfahrens die >chemisch ' gedachten Krankheitsursachen qualitativ und quantitativ zu bestimmen. " ${ }^{34}$ Thurneysser ist damit auch »ein frühes Beispiel für die erfolgreiche Einführung eines technischen, apparativen Verfahrens in die medizinische Diagnostik. « ${ }^{35}$

Allerdings beschränkt sich Thurneyssers Methode nicht auf diesen analytischen Aspekt, sondern greift in einem zweiten Schritt wieder auf analogische Denkmodelle zurück. Aus den Stellen des Destillationsgefäßes, an denen sich die Rückstände ablagern, schließt Thurneysser zurück auf die Stellen des menschlichen Körpers, an denen die Krankheit zu lokalisieren ist. Das Harnglas wird in 24 Abschnitte untergliedert, die in Parallelität zum menschlichen Körper stehen, so dass am Harnglas der Ort der Krankheit abzulesen ist. - Eine merkwürdige Verknüpfung von Innovation und Tradition, die allerdings für den Paracelsismus durchaus typisch ist.

34 Morys: Medizin und Pharmazie (s. Anm. 25), S. 77. Ähnlich auch die Einschätzung von Johanna Bleker: Chemiatrische Vorstellungen und Analogiedenken in der Harndiagnostik Leonhart Thurneissers (1571 und 1576). In: Sudhoffs Archiv 60 (1976), S. 66-75.

35 Michael Stolberg: Die Harnschau. Eine Kultur- und Alltagsgeschichte. Köln u. a. 2009, S. 92. Dort S. 89-92 auch grundsätzlich zur historischen Einordnung von Thurneyssers Methoden. 
Thurneyssers neue Technik der Harnprobenanalyse ist aber nicht nur deshalb von Interesse, weil sie den praktisch-technischen Charakter von Thurneyssers Innovationen zeigt, sondern weil auch diese Harnprobenanalyse wiederum eine eminent ökonomische Dimension hat. Neben der Druckerei hat Thurneysser nämlich im Grauen Kloster auch ein chemisches Labor eingerichtet, in dem er Harnproben analysiert. Der Erfolg seiner neuen Analysemethode war so groß, dass ihm diese Harnproben teilweise über weite Entfernungen zugeschickt wurden. Die Kosten für eine Analyse richteten sich dabei nach den finanziellen Möglichkeiten des Auftraggebers, so dass dieselbe Analyse einen regierenden Fürsten erheblich mehr kosten konnte als einen einfachen Bürger: Thurneysser wollte also offensichtlich alle Marktsegmente bedienen. Wer Thurneysser seinen Urin zur Analyse schickte, bekam von diesem dann nicht nur eine ausführliche Analyse dieses Urins, sondern - so gewünscht - auch gleich die entsprechende Medikation aus Thurneyssers eigener Apotheke. Teilweise hatten die Boten, die Thurneysser den Urin brachten, auch gleich das Geld dabei, das die entsprechenden Medikamente kosten würden, die Thurneysser ihnen mit auf den Rückweg gab. Moehsen, der auch in diesem Punkt den Briefwechsel Thurneyssers ausgewertet hat, schreibt, der Urin sei ihm täglich

nicht allein aus der Mark, sondern auch aus Hamburg, Bremen, Lübeck, Strasburg, Basel, Kassel, Augsburg, München, Wien, und aus dem ganzen römischen Reiche, vornemlich aber aus Böhmen, Mähren, Schlesien, Polen und Preussen mit eignen Boten in versiegelten Gefässen zugeschikt, mit 40, 50 und mehr Talern an Gelde, um die Arzneien zu bezahlen, die er verordnen würde. ${ }^{36}$

Fürsten schicken ihm ihre Diener zur Ausbildung, wofür Thurneysser wiederum Lehrgeld verlangte. ${ }^{37}$

Thurneysser bot damit im Grauen Kloster das komplette Programm an, von der chemischen Analyse über die Diagnose bis zu Herstellung und Vertrieb der Medikamente. Neben und parallel zur Harnanalyse erstellte Thurneysser selbstverständlich astro-medizinische Horoskope, insofern die astrologische Diagnose immer parallel zur (al)chemischen verlief - wie es Thurneysser in der Archidoxa und Quinta essentia vorgeführt hatte. Wer also diese Bücher nicht lesen wollte, konnte immer noch beim Meister selbst seine Diagnose und die entsprechenden Medikamente bestellen.

Nicht nur Harnanalysen und Pharmaka bot Thurneysser an, sondern auch das, was man heute »Schönheits-« oder »Pflegeprodukte« nennen würde, wozu

36 Moehsen: Leben Leonhard Thurneissers (s. Anm. 1), S. 128.

37 Ebd., S. 127. 
Öle und Essenzen gehörten, künstliche Perlen und Edelsteine, aber auch Talismane.

Dergleichen Dinge, als die Verfertigung der Perlen, die Nachahmung der Rubine, Smaragde, Saphire, Amethysten usw. in Glas, die Destillazion der Kräuterwasser, das Bernsteinöl; welches man für seine Erfindung hielt, die Tinktur aus Spiesglas, und viele andere jezt bekante Tinkture, Oele, Essenzen und dergleichen, wurden zu der Zeit als Geheimnisse hochgeschätzt: und es waren nur sehr wenige fürstliche Personen, denen er so wichtige Sachen abschreiben ließ. Die Mitteilung einer solchen Kopie von Handschriften, wurde aus Erkäntlichkeit mit hundert und mehr Talern bezahlt. ${ }^{38}$

Dazu kamen die Einkünfte aus dem Verkauf der Bücher, in denen die Herstellung und Anwendung genau dieser astro-(al)chemischen Wirkstoffe erklärt wurde. Das gesamte Universum von Thurneysser war ein sich vernetztes System astro-(al)chemischen Wissens, das als Ganzes ökonomisch nutzbar gemacht worden war. Es war kein bloß gelehrtes Wissen, sondern ein praktisches und finanziell verwertbares Wissen, ein Geschäftsmodell. ${ }^{39}$ Thurneysser war nicht nur (Al)Chemiker, Apotheker und Astrologe, nicht nur Limnologe, Mineraloge, Geologe und Ingenieur, nicht nur Schriftsteller, Verleger und Drucker, sondern in allen diesen Interessen auch Unternehmer, der eine sehr erfolgreiche Firma geführt hat. Thurneysser war ein Markenname, der - für einen kurzen Zeitraum sehr viel wert war.

\section{Thurneysser als Autor, Drucker, Verleger und Prophet}

Moehsen und Kaiser haben Thurneyssers Tätigkeit als Autor, Drucker und Verleger aus seinem an der Staatsbibliothek Berlin gelagerten Nachlass heraus dargestellt, so dass ich die für meine These wichtigen Punkte nur zusammenfassen muss. ${ }^{40}$ Schon bei der ersten, in Münster von Ossenbrug gedruckten Fassung

38 Ebd., S. 124.

39 Eine gewisse Parallele zu Thurneysser könnte in diesem Sinne Georg am Wald darstellen, der um 1590 ein »Panacea-Imperium« aufgebaute hatte. Vgl. Wolf-Dieter Müller-Jahncke: Georg am Wald (1544-1616). Arzt und Unternehmer. In: Joachim Telle (Hg.): Analecta Paracelsica. Studien zum Nachleben Theophrast von Hohenheims im deutschen Kulturgebiet der frühen Neuzeit. Stuttgart 1994, S. 213-304, dort S. 231.

40 Gabriele Spitzer: ... und die Spree führt Gold. Leonhard Thurneysser zum Thurn. Astrologe, Alchemist, Arzt und Drucker im Berlin des 16. Jahrhunderts. Ausstellungskatalog der Staatsbibliothek zu Berlin. 2. Aufl. Wiesbaden 2001. Zu Moehsen vgl. oben s. Anm. 1. Eine Bibliographie der Drucke von Thurneyssers Werken bieten Diethelm Eikermann und Gabriele Kaiser: 
der Archidoxa verwendet Thurneysser enorme Energien auf die Drucklegung. Persönlich überwacht er diese in Münster, wobei sein größtes Interesse der Gestaltung und dem Druck der Abbildungen gilt. Weil die Druckerpresse Ossenbruges sich für die Kupferstiche als nicht geeignet erweist, müssen die Bögen erst nach Dortmund gebracht und dort gedruckt werden. ${ }^{41}$ Trotz all der Mühe ist Thurneysser mit dem Ergebnis höchst unzufrieden. In einer der Vorreden zur

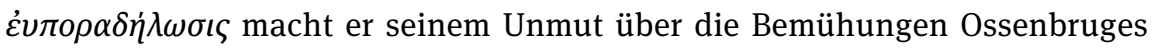
Luft, wenn es dort heißt: »Wardts doch so schlechtlich gmacht dahin | Ob mir gleich vnkost drüber gieng/ | Darfür ich wenig gnueg empfieng/ « (f. A4v).

1570 macht Thurneysser in Frankfurt an der Oder - wo er sich aufhält, um die Drucklegung von Pison zu überwachen - die Bekanntschaft des Kurfürsten Johann Georg von Brandenburg. Nachdem er dessen Gattin erfolgreich einer medizinischen Kur unterzogen hatte, macht dieser ihn (der nie studiert hat, weder Medizin noch ein anderes Fach und nicht einmal Latein, die Sprache der Medizin, beherrscht) zum Leibarzt und stattet ihn mit einem exorbitanten Gehalt aus. In Berlin überlässt er ihm ein ehemaliges Franziskanerkloster, das Graue Kloster. Hier errichtet Thurneysser in den nächsten Jahren ein ökonomisch höchst erfolgreiches Unternehmen, das ihn zu einem reichen, sehr reichen Mann macht. Der Kern dieses Unternehmens sind die Druckerei und das chemische Labor.

$\mathrm{Zu}$ den ersten Büchern, die Thurneysser selbst druckt, gehört die Archidoxa in der bereits beschriebenen, drucktechnisch höchst aufwändigen Gestalt von

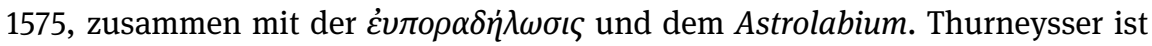
jetzt unabhängig von Druckern und Verlegern, die gesamte Herstellung des Buches liegt in seinen Händen. Damit dürfte auch zu erklären sein, dass auf dem Titelblatt der Archidoxa von 1575 die Tafeln noch vermerkt sind, obwohl sie in dem Band selbst gar nicht mehr enthalten sind. Thurneysser ist die Idee, sie in einem eigenen Band im Supergroßfolio-Format zu drucken, erst während des Druckes gekommen: Er hat gesehen, was drucktechnisch möglich war. Thurneysser ist Herr des gesamten Produktionsprozesses seiner Bücher. Ökonomisch war das höchst erfolgreich, inhaltlich allerdings (bisweilen) fragwürdig. Die gesamte $\dot{\varepsilon} \nu \pi \circ \rho \alpha \delta \dot{\eta} \lambda \omega \sigma \iota \varsigma$, die im Grunde jede im engeren Sinne literarische Gestaltung vermissen lässt und sich über weite Strecken wie ein zweckloses Geplauder liest - allerdings über hunderte von Versen -, dürfte dadurch zu erklären sein, dass Thurneysser gleichsam direkt für die eigene Presse geschrieben

Die Druckwerke von Leonhard Thurneysser zum Thurn (Basel 1531 - Köln 1596). In: GutenbergJahrbuch 87 (2012), S. 171-198.

41 Vgl. Spitzer: ... und die Spree führt Gold (s. Anm. 40), S. 18. 
hat, ohne Plan für den gesamten Text, ohne Lektor und ohne Korrektor, einfach, weil er durch sein Vermögen und seine Ausstattung Herr des gesamten Herstellungsprozesses seines Buchs war.

Damit stünde die Archidoxa von 1575 am Anfang dessen, was am Ende von Thurneyssers steiler - und letztlich kurzer - Karriere zu einem Text wie dem Nothgedrungen Außschreiben (1584) führt, der als Druck auch nur dadurch zu erklären ist, dass hier jemand spricht, der gewohnt ist, alles, was er schreibt, sofort unter die eigene Druckerpresse legen zu können. Das Nothgedrungen Außschreiben ist ein teilweise höchst privates, im Abdruck der juristischen Texte nicht für die Öffentlichkeit bestimmtes Dokument, in dem Thurneysser mit seiner ersten und dritten Gattin, seinem trunksüchtigen und betrügerischen Bruder und der Baseler Obrigkeit abrechnet. ${ }^{42}$ Das Buch scheint aber auch in anderer Hinsicht Ausdruck einer wie auch immer gearteten Krise zu sein, denn kurz darauf lässt Thurneysser sein gesamtes Imperium im Stich, setzt sich nach Rom ab und konvertiert zur katholischen Kirche.

Aber das Nothgedrungen Außschreiben ist in der Geschichte von Thurneyssers drucktechnischen Unternehmungen nur das letzte und merkwürdigste Produkt. Noch einmal sei hier auf das monumentale Pison verwiesen, mit dem Thurneyssers Karriere am Brandenburger Hof begann. Es war das Ungenügen oder zumindest die Unzufriedenheit mit den Druckern in Münster und Frankfurt an der Oder, die überhaupt dazu führte, dass Thurneysser im Grauen Kloster nicht nur ein chemisch-pharmazeutisches Labor, sondern auch eine Druckerei einrichtete. Zeitweise arbeiten für ihn dort an die 200 Angestellte: Drucker, Schreiber, Setzer, Formschneider, Schriftgießer und Korrektoren in der Druckerei, Pharmazeuten und Chemiker im Labor. Das Personal wirbt Thurneysser zum Teil bei anderen Verlagen wie Eichhorn ab. Aus den Abrechnungen mit den Papiermühlen geht hervor, dass Thurneysser sein Papier nicht nur aus dem nahe gelegenen Eberswalde kommen lässt, sondern aus Bautzen, Leipzig und Wittenberg, immer mit dem Anspruch auf höchste Qualität. ${ }^{43}$ Auch die Drucktypen lässt er sich von weither kommen oder beschäftigt eigene Formenschneider. ${ }^{44}$ Wo es sich um Sprachen mit eigenen Schriften handelt, wie im Falle des Onomasticon, lässt Thurneysser sich von Professoren beraten, etwa von dem Orientalisten Elias Hutter oder dem Hebraisten Valentin Schindler.

42 Modernisiert hg. von Will-Erich Peuckert: Der Alchymist und sein Weib. Gauner- und Ehescheidungsprozesse des Alchymisten Thurneysser. Stuttgart 1956.

43 Vgl. Spitzer: ... und die Spree führt Gold (s. Anm. 40), S. 66-68.

44 Vgl. ebd., S. 58-65. 
Dieses Onomasticon, »Gedruckt im Grauen Kloster«, erscheint $1574 .{ }^{45}$ Es handelt sich um den ersten Teil eines paracelsischen Wörterbuchs, dessen vol-

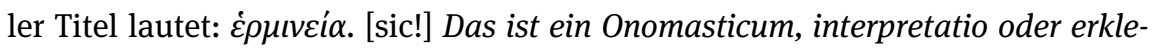
runge [...] Vber die fremden vnd vnbekanten Wörter/Caracter vnd Namen/ welche in den schrifften des Tewren Philosophi, vnd Medici Theoprasti Paracelsi von Hohenheim gefunden werden. Während dieser erste Teil sich noch mit einigen wenigen Schrifttypen begnügt, ist der zweite Teil, der 1583 erscheint, ein drucktechnisches Wunderwerk, indem er nicht nur lateinische, sondern griechische, hebräische, arabische, aramäische, syrische, ja sogar glagolythische (die älteste slawische Schrift, im 9. Jahrhundert für die Mission entwickelt) Wörter in ihren jeweiligen Alphabeten druckt, was Thurneysser selbstverständlich schon auf dem Titelblatt vermerkt: »Jn welchem fast [`fast` wird in dieser Zeit noch verstärkend gebraucht, hier also im Sinne von süberhaupt alle`] jedes Wort/ mit seiner eigenen Schrifft/ nach der Völcker Etymologia oder eigenen art vnd weis zureden/ beschrieben worden ist«.

Was von diesem Anspruch zu halten ist, hat Tobias Bulang in der bisher einzigen Studie zu diesem Werk schon vorgeführt. Teilweise handelt es sich bei den Einträgen um Wissen aus zweiter Hand, schlecht kompiliert und fehlerhaft transkribiert, was schon manchen zeitgenössischen Lesern aufgefallen ist. Die humanistische Elite der Zeit war mit einem solchen Werk sicherlich nicht zu beeindrucken - zu offensichtlich war, dass der Autodidakt Thurneysser (der, wie gesagt, erst in seiner Berliner Zeit Latein gelernt hat) diese Sprachen nicht beherrschte. Das einfachere Volk dagegen warf ihm aufgrund seiner angeblichen Sprachkenntnisse Teufelsbündschaft vor, so dass sich Thurneysser in der Folge von zwei Seiten angegriffen sah.

Die Schrifttypen, die für den Druck des Onomasticon notwendig waren, führt Thurneysser noch einmal in einer eigenen Publikation vor. Ähnlich wie das Astrolabium zur Archidoxa gehört, auch wenn es als eigener Band gedruckt worden ist, erscheint die Tafel etlicher Sylben als separater Band im selben Jahr. Ihr voller Titel lautet:

Tafel etlicher Sylben/ durch welche zwo vnd dreissig führnehmer/ gemeiner/ noch dieser zeit gebreuchlicher oder bekanter/ Vnd dann acht vnd sechtzig frembder [...] Sprache/ in-

45 Grundlegend zum Onomasticon sind die Arbeiten von Tobias Bulang, vgl. Bulang: Überbietungsstrategien (s. Anm. 9), ders.: Intrikate Expertise - Die magische Pharmakognostik des Leonhard Thurneysser zum Thurn. In: Hedwig Röckelein, Udo Friedrich (Hg.): Experten der Vormoderne zwischen Wissen und Erfahrung. Berlin 2012, S. 118-136, und ders.: Zur Diskursivierung pflanzenkundlichen Wissens bei Leonhard Thurneysser zum Thurn. In: Thorsten Burkard u. a. (Hg.): Wissensdiskursivierungen. Themen, Medien und Räume des Wissens vom 14. bis zum 18. Jahrhundert. Berlin 2013, S. 39-61. 
halts der fünff Vocalium/ vnd anderer Regalischen vnd Ministerischen Accenten/ Puncten vnd Virgulen [...] nach art der fürgestalten Siebentzehen sonderlichen Schriefften/ geschrieben/ gelesen/ vnd außgesprochen werden mögen. Mit beysatz etlicher [...] fremden Alphabeten/ welche in dem andern Theil des Onomastici nicht begriffen.

Ähnlich wie das Astrolabium ist diese Tafel - schon allein von ihrem Format her: 82,8 x 56,2 cm - ein drucktechnisches Meisterwerk, »ein beachtliches Anschauungsobjekt für die Leistung seiner Druckerei «. ${ }^{46}$ Aus den Briefen von Thurneyssers Drucker geht hervor, was für ein Aufwand es war, eine solche Tafel zu drucken. ${ }^{47}$ Auch hier muss sich deshalb der Eindruck aufdrängen, dass es Thurneysser nicht nur darum ging, eine ungeheure und alles überbietende Gelehrsamkeit vorzuführen, sondern genauso auch die technischen Möglichkeiten seiner Druckerei ${ }^{48}$ Die Tafel war, genauso wie das Astrolabium, ein Muster und Modell, mit dem Thurneysser zeigte, wozu seine Druckerei im Stande war. Es war Teil seiner >Marketing-Strategie`, wie man das wohl heute nennen würde.

Aber die drucktechnischen Innovationen Thurneyssers beschränken sich nicht auf die Archidoxa und das Onomasticon. In seiner Confirmatio concertationis (1576) führt Thurneysser nicht nur seine neue Technik der Harnprobenanalyse vor, sondern illustriert die daraus resultierenden Heilmethoden am menschlichen Körper. Um diesen Körper darzustellen, entwickelt er wiederum eine neue Drucktechnik, die bis heute in Lehrbüchern zur Anwendung kommt, um das Körperinnere im Buch darzustellen: Thurneysser erfindet die aufklappbaren Elemente, die man anheben kann, um das Innere des menschlichen Körpers zu sehen. ${ }^{49}$ Die Qualität der Abbildungen ist, was ihre künstlerische und anatomische Detailgenauigkeit betrifft, nicht im Entferntesten mit denen von Andreas Vesalius' vergleichbar, dessen De humani corpore fabrica in Basel 1543 bei Oporin gedruckt worden war. Dennoch dürfte dieses Werk das Vorbild Thurneyssers gewesen sein. ${ }^{50}$ Seine Idee war auch hier, nicht nur eine neue medizinische Therapie zu propagieren, sondern sie auch selbst zu vermarkten. Zumindest

46 Vgl. Spitzer: ... und die Spree führt Gold (s. Anm. 40), S. 92.

47 Vgl. ebd.

48 Dies bereits die These von Bulang, der ich mich nur anschließen kann.

49 Darauf hingewiesen hat zuerst Moehsen: Leben Leonhard Thurneissers (s. Anm. 1), S. 69.

50 Wie die anatomischen Darstellungen Vesals auf Sektionen zurückgehen, so betont im Übrigen auch Thurneysser, dass seine Darstellungen auf Sektionen zurückgehen. Während der ausgedehnten Reisen in der ersten Hälfte seines Lebens habe er auf Schlachtfeldern solche Sektionen durchgeführt, später sei ihm die Leiche einer Hingerichteten zur medizinischen Untersuchung überlassen worden. Schon Moehsen: Leben Leonhard Thurneissers (s. Anm. 1), S. 69 hat zudem vermutet, dass Thurneysser den Vorlesungen, die Vesal 1542-46 in Basel gehalten hat, als junger Mann beigewohnt hat. 
in diesem Punkt sind die Erwartungen Thurneyssers aufgegangen: Aus den Abrechnungen der Messen geht hervor, dass die Confirmatio concertationis ein Bestseller war. ${ }^{51}$

Ein Werk von allerhöchstem drucktechnischem Anspruch ist auch das Kräuterbuch, das 1578 gleichzeitig in deutscher und lateinischer Fassung erschien: Historia sive descriptio plantarum omnium, mit dem deutschen Titel die $B e$ schreibung Influentischer, Elementischer und Natürlicher Wirckungen, Aller fremden unnd Heimischen Erdgewechssen, auch jrer Subtiliteten, sampt warhafftiger und Künstlicher Conterfeitung derselbigen. Nur der erste Band dieses auf zehn Bände angelegten Werkes ist erschienen. Auch diesem Werk hat Tobias Bulang bereits einen grundlegenden Aufsatz gewidmet, in dem er das »exorbitante Überbietungsunternehmen« dieses Kräuterbuches vorführt:

Nicht weniger als 1600 Kräuterstücke hat Thurneysser von teils hochrenommierten Formschneidern anfertigen lassen [...], lediglich 37 davon finden sich in dem veröffentlichten Band, die anderen wurden erst 1673 im `Herbarium ^ des Thomas Pancovius gedruckt. Der erste Band ist als Einleitung vorgesehen, welche die Prinzipien der Folgebände erläutert und 37 Doldenpflanzen (Umbelliferen) behandelt. Rechnet man den in der Vorrede des Bandes angekündigten Gesamtbestand von 1923 Pflanzen-Abbildungen entsprechend der pro Bild verwendeten Textmenge auf, ergeben sich für jeden der geplanten Folgebände $209 \mathrm{zu}$ behandelnde Pflanzen, womit für jeden Band ca. 800 Seiten zu veranschlagen wären. Und dies stellt selbst im Vergleich zu den imposanten Kräuterbüchern des 16. Jahrhunderts ein exorbitantes Überbietungsunternehmen dar. ${ }^{52}$

Während das vermittelte Wissen wenig überraschend ist und die (von Thurneysser proklamierte) Umsetzung der paracelsischen Signaturenlehre eher bescheiden ausfällt, ist Thurneyssers Umgang mit dem Layout der Druckseite äußert innovativ. Die zweispaltig bedruckten Seiten unterbrechen den Fließtext mit kleinen Abbildungen und Illustrationen sowie mit modern anmutenden, gerahmten Einschüben. Bulang spricht von einer »außergewöhnlich innovative[n] und originelle[n] Handhabung der Druckseite, auf der sich eine Hybridisierung aller möglicher Traditionen findet «. ${ }^{53}$

Auch für das Kräuterbuch hat Spitzer aus dem handschriftlichen Nachlass rekonstruiert, was für einen drucktechnischen Aufwand die Herstellung bedeutet hat. ${ }^{54}$ Thurneysser beschäftigte mehrere Formenschneider mit der Herstellung der Druckvorlagen, u. a. in Leipzig, Prag, Halle und Basel, neben seinen eigenen Angestellten in Berlin. Aber auch die Fortsetzung dieses Unternehmens

51 Vgl. Spitzer: ... und die Spree führt Gold (s. Anm. 40), S. 84.

52 Bulang: Diskursivierung pflanzenkundlichen Wissens (s. Anm. 45), S. $48 \mathrm{f}$.

53 Ebd., S. $60 \mathrm{f}$.

54 Vgl. Spitzer: ... und die Spree führt Gold (s. Anm. 40), S. 84-89. 
scheiterte am Größenwahn Thurneyssers. Obwohl die Abbildungen für die weiteren Bände vorlagen, wurde nur der erste Band gedruckt. Wie aus dem Briefwechsel hervorgeht, wollte Thurneysser den Druck später in Basel fortsetzen und erkundigte sich bei Froben, dem angesehensten Basler Drucker dieser Zeit, nach dessen Bedingungen. Froben gab ihm jedoch einen Rat, der ihm zutiefst zuwider gewesen sein dürfte: Er solle eine kleinere Schrift wählen, auf die Marginalnoten verzichten und die Zahl der Illustrationen verkleinern, damit er nicht so viel Papier verbrauche, den Setzerlohn minimiere und preiswertere Bücher herstellen könne. ${ }^{55}$

Buchgeschichtlich höchst innovativ ist auch ein letztes, hier zu nennendes Produkt des Autors, Verlegers und Druckers Thurneysser, nämlich seine Kalender. ${ }^{56}$ Kalender gehören zu den ältesten Erzeugnissen des Buchdrucks überhaupt und erfreuten sich größter Beliebtheit. Seinen ersten Kalender, dem brandenburgischen Kurfürsten gewidmet, druckt Thurneysser 1571 noch bei Eichhorn in Frankfurt an der Oder. Er unterscheidet sich in seiner drucktechnischen Erscheinung wenig von anderen zeitgenössischen Kalendern. In mehreren Spalten bietet er für jeden Tag des Jahres die astronomischen Angaben (Mondphase, Regenten), die Termine des Kirchenjahres, Wetterprognosen, die für diesen Tag vorgesehenen Bibelstellen (Psalmen, Altes und Neues Testament), sowie medizinische und astrologische Empfehlungen. Diese Empfehlungen betreffen bestimmte Tätigkeiten, die sich unter diesem Sternzeichen besonders empfehlen oder verbieten, wie z. B. Haare schneiden, Kinderentwöhnen, Baden sowie landwirtschaftliche Tätigkeiten wie Säen, Ernten oder Holzfällen. Diese Empfehlungen waren Grundlage der in der Frühen Neuzeit ubiquitären, sogenannten >Tagewählerei<, also der Empfehlung bestimmter Tage für bestimmte Tätigkeiten. In einer weiteren Spalte bietet Thurneysser zwei Verse zur »belüstigung des lesers«, die den Jahrestag eines geschichtlichen Ereignisses (insbesondere mit Bezug zur brandenburgischen Geschichte) an diesem Tag betreffen, analog zu den auch heute noch verbreiteten Kalendersprüchen.

$\mathrm{Zu}$ den Grundlagen der `Tagewählerei` gehört, dass Thurneysser insbesondere die Tage notiert, an denen sich bestimmte medizinische Praktiken besonders

55 Vgl. ebd., S. 89.

56 Vgl. dazu die buchgeschichtlichen Studien von Fritz Juntke: Über Leonhard Thurneisser zum Thurn und seine deutschen Kalender 1572-1584. In: Archiv für Geschichte des Buchwesens 19 (1978), S. 1349-1400, und ders.: Über Leonhard Thurneisser zum Thurn und seine Schriften nach der Flucht aus Berlin (1584). In: Archiv für Geschichte des Buchwesens 21 (1980), S. 679-718. 
empfehlen, wie z. B. Aderlass. ${ }^{57}$ Präziser als andere Kalender der Zeit verschreibt Thurneysser darüber hinaus einzelne Medikamente präventiv für astrologische Konstellationen. So hat er ein eigenes Druckzeichen für »Artzney/ so Pillulen/ Croco/ vnd dergleichen truckner weis ingeben «, im Gegensatz zu anderen Zeichen, die für diesen Tag eine Arznei bedeuten, »so in Ladwergen oder succi gestalt zugericht« oder »in liquoris gestalt oder tränck « verabreicht werden müssen (f. B ij ${ }^{r}$ ). Die Kalender verhalten sich damit analog zu der Selbstmedikation, wie sie die Archidoxa ermöglicht.

Dieser und die folgenden Kalender Thurneyssers waren extrem erfolgreiche Verlagsprodukte. Sie wurden teilweise in einer Auflage von bis zu 1200 Exemplaren gedruckt und waren auch dann noch schnell ausverkauft. In der Korrespondenz Thurneyssers finden sich Briefe anderer Drucker und Buchhändler aus Frankfurt am Main, Nürnberg, Wien, Prag und Ingolstadt, die um die Erlaubnis bitten, seine Kalender nachdrucken zu dürfen, selbstverständlich gegen angemessene Beteiligung. ${ }^{58}$ Eine solche Nachfrage war in der Frühen Neuzeit nicht selbstverständlich. Im Gegenteil, die Klage über unerlaubte Nachdrucke ist allgegenwärtig, auch im Falle Thurneyssers, worauf dieselben Drucker und Verleger hinweisen, um ihrer Bitte Nachdruck zu verleihen. ${ }^{59}$ Man bat um die Erlaubnis für Übersetzungen ins Lateinische, Ungarische und Böhmische. ${ }^{60}$ Teilweise scheint die Nachfrage so groß gewesen zu sein, dass Thurneysser ihr mit seiner eigenen Druckerei im Grauen Kloster nicht mehr gerecht werden konnte und andere Druckereien beauftragen musste. Ein weiteres Indiz für den ökonomischen Erfolg der Kalender ist die Tatsache, dass unter Thurneyssers Namen Kalender publiziert wurden, die gar nicht von ihm sind. Das ist bekannt, weil Thurneysser 1591 deshalb eine Admonitio Oder Warnung An alle Ehr und Warheit liebenden Menschen, veröffentlicht »auß deren eygentlich zu erkennen, daß der falsche LugenKalender, so verschiener Herbstmeß Anno $1590 \mathrm{zu}$ Franckfort und anderswo offentlich verkaufft worden [...] durch etliche Fälscher und Verleumbder, frefflich zugemessen worden«. (Rorschach 1591) Noch in den Jahren nach 1600, als Thurneysser bereits gestorben ist, erscheinen Kalender unter seinem Namen, was vielleicht das deutlichste Indiz für den Verkaufserfolg ist, den der Name Thurneysser auf einem Kalender bedeutet haben muss.

57 Zur pharmazeutischen Bedeutung der Kalender vgl. den Überblick bei Wolf-Dieter MüllerJahncke: Medizin und Pharmazie in Almanachen und Kalendern der frühen Neuzeit. In: Joachim Telle (Hg.): Pharmazie und der gemeine Mann. Hausarznei und Apotheke in deutschen Schriften der frühen Neuzeit. Weinheim, New York 1988, S. 35-42.

58 Vgl. Moehsen: Leben Leonhard Thurneissers (s. Anm. 1), S. 120.

59 Vgl. Spitzer: ... und die Spree führt Gold (s. Anm. 40), S. $106 \mathrm{f}$.

60 Vgl. Moehsen: Leben Leonhard Thurneissers (s. Anm. 1), S. 120. 
Besonders viel Aufsehen erregte dabei eine Neuerung, die sich wohl 1576 zum ersten Mal findet ${ }^{61}$ und in der Folge sich als eine äußerst erfolgreiche Vermarktungsstrategie herausstellte. Bei einzelnen Tagen druckte Thurneysser rote Versalien, die besondere Ereignisse vorhersagen sollten, aber nur von ihm aufgelöst werden konnten. Allerdings löste er diese Versalien entweder nur rückblickend auf, um die Richtigkeit seiner Vorhersage zu demonstrieren, oder - wenn er sie im Vorhinein auflöste - nur brieflich gegen Zusendung von Geld und die Versicherung, dass der Empfänger seine Erklärung geheim halte. So heißt es in der Vorrede zum Kalender für das Jahr 1781, gerichtet gegen die »Neider«, er würde jedem, der ihm das Geld nach Berlin schicke, einen »Extracten oder Clavirum [sic! - gemeint sein dürfte >clavem`, also ১Schlüssel«]« zustellen. Wenn er eine solche Erklärung der Versalien nicht drucke, so nur deshalb, weil sie erstens zu umfangreich und damit zu teuer wäre und zweitens er verhindern wolle, dass andere mit seiner Arbeit reich würden, indem sie diese Erklärungen nachdruckten (f. A4v).

Offenkundig aufgrund einer stärker werdenden Kritik an seiner Person und seinen Büchern verfasst Thurneysser 1580 die

Impletio oder verheissung. Darinn nicht allein gründlicher und außfürlicher verstandt aller Character/ verkürtzter wörter/ oder sonst verborgner reden/ sonder auch warhafftiger Bericht deren ursachen/ neben den Fundamenten seines Glaubens/ Distillirens/ Curirens/ Prognosticirens/ Frembder Sprachen Redens/ Bücherschreibens/ Kreuterkennens/ Wanderens/ Harnprobirens/ vnd anderer seiner betriben vnd hendlen/ gegeben wird.

Es handelt sich also um eine Art Universalrechtfertigung, die vorführt, womit Thurneysser bei seinen Zeitgenossen Verdacht erregte. Auch hier hat Thurneysser drucktechnisch wieder nicht gespart, indem er eigens einen Kupferstich für das Titelblatt anfertigen ließ, der ihn selbst als Kriegsmann und Gelehrten zeigt, der seine Gegner in den Staub tritt. Seine Sprachkenntnisse und Drucktypen werden vorgeführt, indem auf der ersten Seite (ohne erkennbaren inhaltlichen Bezug) der 118. Psalm in drei Alphabeten abgedruckt wird. Nachdem Thurneysser in der Folge erklärt hat, wie er so viele Sprachen beherrschen kann und wie er seine Kalender erstellt, kommt er auf die geheimnisvollen Versalien zu sprechen, die er jetzt - rückblickend - für den Kalender desselben Jahres erklärt. ${ }^{62}$ Teilweise wer-

61 Der Kalender aus dem Jahr 1576 ist derzeit digital noch nicht zugänglich, meine Kenntnis beschränkt sich auf die Kalender der Jahre 1577-1583. Zu den Kalendern Thurneyssers vgl. den Eintrag bei Klaus-Dieter Herbst: Biobibliographisches Handbuch der Kalendermacher von 1550 bis 1750, digital zugänglich unter https://www.presseforschung.uni-bremen.de/dokuwiki/ doku.php?id=thurneysser_leonhardt.

62 Auch hier greife ich ein Argument auf, das bereits Bulang: Die Welterfahrung des Autodidakten (s. Anm. 29), S. $528 \mathrm{ff}$. entwickelt hat. Ich übernehme auch seine Beispiele. 
den sie mit entwaffnender Simplizität aufgelöst, etwa wenn »H.A.I.« am zweiten Januar als »Hic annus incipit. Diß Jar wirdt sich anfahen/ oder beginnen.« (f. G ij ${ }^{r}$ ) erklärt wird. »M.T.R.« am 20. Januar dagegen bedeutet »Minatur tribus Regibus. Die drewet dreyen Königlichen Personen/ da der ein an dem Mari mediterraneo. Der ander etwas an den Tartern. Der dritt ein theil der Gallier regiert.« (f. G ij „E.M.Q.I.« am 22. Januar bedeutet »Episcopus magnus quidam interibit. Ein grosser fürnemer Bischoff bleibt im lauff/ oder geht zu grund.« (f. G ij ${ }^{\mathrm{v}}$ ) Eine besondere Pointe ist bei den Versalien, dass sie laut Impletio für jeden Monat in einer anderen Sprache aufgelöst werden müssen: im Januar lateinisch, im Februar französisch, im März böhmisch, im April ungarisch, im Mai hebräisch, im Juni deutsch, im Juli griechisch, im August äthiopisch, im September polnisch, im Oktober syrisch, im November vandalisch und im Dezember arabisch. Die Auflösung der Versalien gibt Thurneysser also auch hier wieder die Möglichkeit, seine umfangreichen Sprachkenntnisse und Drucktypen vorzuführen.

Die Kalender Thurneyssers mögen bizarr anmuten, waren aber im 16. Jahrhundert nicht ganz ohne Vorbild. Die Kalender von Nostradamus mit ihren rätselhaften Versen waren von 1555-1567 erschienen und erfreuten sich einer unglaublichen Beliebtheit, die sich in zahlreichen Nachdrucken und Nachahmungen spiegelt. Schon 1555 waren zudem die Prophetien des Nostradamus erschienen, die - ganz ähnlich den Werken von Thurneysser - von humanistisch-antiquarischer Gelehrsamkeit inspiriert waren und mit ihrer gesuchten Dunkelheit und Unverständlichkeit die antiken Orakel nachahmten. Nostradamus und Thurneysser gemeinsam ist darüber hinaus das Desinteresse an den mathematischen Grundlagen der Astrologie. Die Horoskope von Nostradamus waren teilweise grob fehlerhaft, was in einem merkwürdigen Kontrast zur Präzision seiner Vorhersagen stand. ${ }^{63}$

Analog zu Nostradamus war Thurneysser mit seinen Vorhersagen äußerst erfolgreich. Moehsen, der den handschriftlich erhaltenen Briefwechsel Thurneyssers gelesen hat, berichtet, dass Thurneysser »auf hohes Verlangen« hin 1580 damit begonnen habe, die Versalien handschriftlich bereits im Voraus zu erklären:

Wie es bekant wurde, daß er dergleichen geschriebene Auslegungen beisezte: so wurden sie sehnlich verlangt. Markgraf Joachim Friedrich zu Halle war der erste, welcher schon 1575 einen Kalender verlangt, >in welchem er so viel möglich vermerken möcht, die Sachen und Hände, so jedes Tages in ermeldetem seinem Kalender gesetzet, als Mord, Brand, Aufruhr, Abgang hoher Personen, falsche Praktiken, und dergleich, welches Orts sich solches vornemlich zutragen würde, welches er ihm vertraulich zu erkennen geben möchte. Der Markgraf war damit sehr heimlich; kaum aber hatte es die Markgräfin Katharina, seine Gemalin, erfahren: so ersuchte sie Thurneissern, sihr einen Almanach zu schikken,

63 Vgl. die Nachweise bei Pierre Brind'Amour: Nostradamus astrophile. Les astres et l'astrologie dans la vie et l'œuvre de Nostradamus. Ottawa 1993. 
fein deutlich und eigentlich beigeschrieben, wie man jegliches verstehen soll, und ihr nichts verhalten, so wie er ihn ihrem Gemal geschikt hätte. Dem Administrator in Preussen, Markgrafen George Friderich hatte er dergleichen Auslegungen der Buchstaben, nur auf die Monate Januar und Februar 1583 beigeschrieben, zugeschikt; wofür er ihm dreißig Taler auszalen ließ, mit Bitte, für diesesmal damit vorlieb zu nehmen. Er ersuchte ihn auch, in den andern Monaten auf alle Tage die Begebenheiten zu spezifiziren: seine Erkäntlichkeit würde nicht fehlen. Auf der königlichen Bibliothek ist ein, mit Papier durchschossener und in Samt gebundener, Kalender von 1580, wo er dergleichen Prophezeiungen, wie es scheint, im voraus zum Dienst der Markgräfin Katharina erklärt hatte, und beischreiben lassen; und da er aus den Nativitäten der fürstlichen Personen Glük und Unglük wußte: so warnete er zuweilen darin, und schrieb ihnen und den fürstlichen jungen Herrschaften Diät, Lebensregeln und, an gewissen Tagen und Konstellazionen zu gebrauchende, Arzeneien vor. ${ }^{64}$

Diese Arzneien stellte Thurneysser in seinem Labor selbst her und lieferte sie den fürstlichen Kunden zusammen mit den Horoskopen. Die Kalender sind damit vielleicht der deutlichste Beleg für die Behauptung, dass wir es bei Thurneysser mit einem marktstrategisch sehr hellsichtigen Unternehmer zu tun haben. Denn auch die Kalender mit ihren Abkürzungen sind vor allem eines: eine äußerst innovative Art, das neue Medium des Buchdrucks ökonomisch geschickt einzusetzen. Letztlich, so lautet meine These, ist die Archidoxa mit ihren Planetentafeln Ausdruck genau derselben Idee, die auch hinter den Kalendern steht. Die Archidoxa soll mit dem Astrolabium dem Käufer die Möglichkeit verschaffen, sich selbst sein Horoskop $\mathrm{zu}$ erstellen und sich (durch gleichzeitige Konsultation der Quinta essentia) die entsprechende Medikation zu verschreiben. Der Kauf zweier Bücher Thurneyssers ersetzt die teure Expertise eines Astrologen und Pharmazeuten.

Insbesondere ein Werk, das (jedenfalls in seiner Beschreibung im Druck) erst nach dem Tod Thurneyssers erschien, bestätigt diese These vielleicht besonders nachdrücklich. Es handelt sich um die

Reise und Kriegs-Apotecken, Darinnen nicht allein die Beschwerlichsten Kranckheiten an des Menschen Leibe, so ausser und innerhalb Krieges, die Menschen zubefallen pflegen, vermeldet, sondern auch die geheimen vnd fürtrefflichesten Medicamenta chimica, an Tincturen, Essentien, Oelen/ Magisterien, Elixiren, Arcanen, Extracten, vnd dergleichen/ nach jhren kräfften/ gebrauch vnd praeparationen beschrieben werden. Wie sie der Ehrnvheste vnd Hocherfahrne Herr Leonhard Thurneisser zum Thurn/ weiland Churf. Brandenb. bestalter Leibmedicus an Keiserlichen/ Königlichen/ Chur vnd Fürstlichen/ Auch andern fürnemen Personen/ viel Jahre mit grossem nutze vnd lob practiciret/ vnd gebraucht hat. (Leipzig 1602)

Das Buch enthält - einmal mehr - eine Rezeptsammlung Thurneyssers, einschließlich Dosierungsanleitungen (S. 47: »Für den Husten. Aurum potabile, Ol Succini,

64 Vgl. Moehsen: Leben Leonhard Thurneissers (s. Anm. 1), S. $121 \mathrm{f}$. 
argent potabile ana 2 tropffen in Wein«) und Preisliste (S. 71: »Oleum tartari correctum, mit dem Magisterio Radicis, für groß hauptwehe/ auff sechs mahl zugebrauchen/ kostet drey thaler«). Am Ende der Preisliste findet sich die »Nota«:

Von diesem Taxt [gemeint ist die >Taxatio`, wie die Preisliste überschrieben ist] ist Herr Thurneusser so Reich worden/ weil domals diese Medicamenta gar newe vnd seltsam waren/ jtzunder werden sie viel in einem geringern kauff bekommen/ weil die kunst gemein worden ist. (S. 79)

Auch an dieser Reise- und Kriegsapotheke ist die eigentliche Pointe also, dass sie den Arzt und Apotheker auf einmal überflüssig macht.

\section{Thurneysser als Gegenstand einer Wissensgeschichte}

Abschließend möchte ich noch einmal auf die methodische Frage zurückkommen, die ich am Anfang dieses Beitrags formuliert habe. Aus der Perspektive des 19. Jahrhunderts und seines Begriffs einer experimentell verfahrenden >Naturwissenschaft war die Astrologie Thurneyssers Aberglauben, seine Kalender Betrug und Bauernfängerei, seine Alchemie Narrheit und sein Paracelsismus ein pharmaziehistorischer Irrtum. Vor dem Hintergrund eines Ideals von sexperimenteller Naturwissenschaft $\iota$, in dem Wissen ausschließlich an eine experimentell gewonnene Erkenntnis geknüpft ist, als ıreines Wissen` angeblich frei von ökonomischen Interessen, sind die Archidoxa und die Quinta essentia kaum als ernst zu nehmendes Wissen zu erkennen. Thurneysser, der als Verleger seine eigenen Texte druckt und vermarktet, ist weit weg von der Idee eines Naturwissenschaftlers, der sein Wissen in unabhängigen Fachzeitschriften publiziert. Die Tatsache allein, dass beide Texte als Dichtungen verfasst sind, genügt manchem Historiographen der >Naturwissenschaften، schon, sie als Ausdruck eines Naturwissens nicht mehr ernst zu nehmen. Von der fatalen Unterscheidung zwischen einer (mehr oder weniger) irgendwie smystischen und einer >wissenschaftlichen Chemie der Moderne ganz zu schweigen.

Wer sich mit der Archidoxa und der Quinta essentia beschäftigt, braucht eine wissenschaftshistorische Perspektive, muss sich aber vom Begriff einer Wissenschaft, gedacht als experimentelle Naturwissenschaft, freimachen. Eine ähnliche Forderung wird man an die Literaturwissenschaft richten müssen. Aus der Perspektive einer Literaturwissenschaft, die ihren Gegenstand im Sinne des 18. Jahrhunderts als ıschöne Literatur` versteht, ist über die Archidoxa und die Quinta essentia nichts zu sagen. Schon mit der historisch unhaltbaren Kategorie 
der `Lehrdichtung` (die, wie der Begriff der `Literatur`, dem 18. Jahrhundert entstammt) verbaut man sich den Zugriff auf diese Texte als den Versuch, das Wissen der Alchemie und Astrologie medial zu vermarkten.

Die konkrete Form der Archidoxa mit ihrem merkwürdigen dreispaltigen Druck und ihrer Chiffrenschrift genauso wie die Quinta essentia, die mit der »Heimlichkeit« hausieren geht, sind Ausdruck der Tatsache, dass Thurneysser seine Bücher verkaufen will. Das ist für diese Zeit nicht selbstverständlich und unterscheidet ihn massiv zum Beispiel von den Büchern, die ein Professor der Medizin dieser Zeit publiziert hat (dem es, wie heute, wahlweise um Akkumulation von Ansehenskapital oder um Argumente geht). Thurneysser partizipiert mit der Archidoxa am elitären Wissen der Astrologie und mit der Quinta essentia am geheimnisvollen, rätselhaften Charakter der Alchemie, indem er beides marktstrategisch nutzbar macht. Die gesamte, buchtechnisch konkrete Erscheinungsform beider Werke übernimmt den rätselhaften Charakter der Alchemie, ohne selbst noch eigentlich rätselhaft zu sein. Wie die Archidoxa mit ihren Quellennachweisen in den Marginalien eine humanistische Gelehrsamkeit vortäuscht, so will sie mit ihrer Versform am Charakter uralter Weisheitslehren partizipieren. Es hat deshalb keinen Sinn, die Archidoxa und Quinta essentia aus ihrem historischen Kontext herauszulösen und als `Literatur`verstehen zu wollen.

Wie in der methodischen Vorbemerkung angekündigt, hat dieser Beitrag deshalb (hoffentlich) gezeigt, dass ein Verständnis der Archidoxa und der Quinta essentia die medienhistorische genauso wie die chemiehistorische, die lokalhistorische genauso wie die biographische Dimension in Betracht ziehen muss. Es braucht einen wissenschaftshistorisch, genauso wie ideen- und sozialgeschichtlich geschärften Blick, der die medienhistorischen Gegebenheiten (die wachsenden Möglichkeiten des Buchdrucks) genauso wie die ökonomischen Entwicklungen einbezieht, um die Texte Thurneyssers zu verstehen. Sichtbar wird aus dieser Perspektive Thurneysser als Unternehmer und Erfinder, als Autodidakt und sself made man', als Drucker und Verleger. Wie soll man einen solchen Zugriff nennen? - Ich würde den Begriff der Wissensgeschichte vorschlagen, ${ }^{65}$ durchaus im Bewusstsein, dass dieser Begriff methodisch leer bleibt. Gerade deshalb hat er allerdings den Vorteil, den Zumutungen und Verkürzungen einer sich dezidiert als solcher verstehenden Ideen- oder Sozialgeschichte, einer Literatur- oder Wissenschaftsgeschichte zu entgehen.

65 Vgl. Volkhard Wels: Die Alchemie der Frühen Neuzeit als Gegenstand der Wissensgeschichte. In: Peter-André Alt u. a. (Hg.): Magia daemoniaca, magia naturalis, zouber. Schreibweisen von Magie und Alchemie in Mittelalter und Früher Neuzeit. Wiesbaden 2015, S. 233-265. 